\title{
Locality in exceptions and derived environments in vowel harmony
}

\section{Shakuntala Mahanta}

Received: 12 September 2008 / Accepted: 11February 2011

\begin{abstract}
The regular realm of vowel harmony in Assamese consists of right-to-left regressive [ATR] harmony. In contrast with this regular pattern of vowel harmony, the exceptional Assamese processes dealt with in this paper are symptomatic of the behavior of a pair of morphemes that trigger additional processes not seen elsewhere in the language. This pair of morphemes allows raising of the otherwise opaque vowel /a/ and fronting/backing of /a/ depending on the [Back] quality of a mid vowel adjacent to /a/. Raising is strictly local in the presence of preceding high and low vowels, but there is also another pattern which shows backness assimilation to a previous vowel if there are mid vowels preceding the $/ \mathrm{a} /$ of the input. This exceptional raising occurs to allow [ATR] harmony to spread regressively by changing the $[-\mathrm{ATR}]$ low vowel into a $[+\mathrm{ATR}]$ mid vowel. I analyse these cases within Optimality Theory (Prince and Smolensky 1993/2004) and show that these exceptional occurrences are morpheme-specific. It is also shown that these exceptional occurrences lend themselves to an account based on indexation of markedness constraints (Flack 2007; Ota 2004; Pater 2000, 2006, 2009). Consequently, the Assamese examples show that indexed markedness constraints are able to deal with an exceptional alternation where a low vowel undergoes harmony locally. This article also shows that an emergence of the unmarked analysis is required to account for the low back vowel that alternates with a front vowel if there is a preceding front vowel. This article goes beyond the problems encountered in Assamese, and claims that there is no need to invoke locality in exceptional blocking in vowel harmony, as both exceptional and non-exceptional blocking in vowel harmony are always local and bounded. The goal of this paper is to shed light on exceptional and emergent processes, arguing that they are always local and governed by strong universal properties of grammar.
\end{abstract}

Keywords Morpheme-specific exceptions; lexical indexation; locality; vowel harmony; emergent unmarkedness; Assamese

\section{Introduction}

Assamese has eight surface vowels, and it exhibits regressive [ATR] harmony: the high vowels /i/ and $/ \mathrm{u} /$ systematically trigger [+ATR] in all the extant [-ATR] high and mid vowels in the language (i.e. /E/, $/ \mathrm{J} /$ and $/ \mathrm{u} /$ ) except for in the $[-\mathrm{ATR}]$ low vowel $/ \mathrm{a} /$. In this language, exceptional patterns emerge when a root morpheme containing the vowel /a/ is harmonized to either [e] or [o] by the presence of the suffixes /-ija/ and /-uwa/. In this paper I present the intricacies of exceptional triggering of [ATR] vowel harmony by the two morphemes /-ija/ and /-uwa/ in Assamese, and I also present an analysis of this exceptional pattern within the theory of lexical indexation in Optimality Theory.

Section 1 presents a general background to Assamese vowel harmony, and delineates the nature of the sequential markedness constraints that will be employed to analyze regressive vowel harmony. Section 2 deals with data and problems relating to exceptional triggering of harmony by the affixes /ija/ and /-uwa/ in Assamese. Its subsections illustrate the theoretical precept of locality in exceptionality. Section 2 also discusses the typological implications of the patterns of exceptionality thus far encountered in languages. Section 3 discusses the untenability of alternative approaches to exceptions in vowel harmony. Section 4 discusses the /a/-raising data, and offers an emergence of the unmarked solution to the problem encountered in these data. The subsections in 4 discuss alternative theoretical approaches, and the paper ends with a conclusion in Section 5.

The main thrust of this paper is to discuss exceptions in vowel harmony in order to broaden our understanding of exceptional processes, with reference to data from a hitherto under-described language. In order to do so, we must first understand the regular vowel harmony pattern of Assamese. To this extent, Section 1.1 presents a descriptive backdrop that acquaints the reader with the vowel system and the processes of vowel harmony in the language.

1.1 Introduction to Assamese vowel harmony 
Assamese has the eight surface vowels [i, e, $\varepsilon, \mathrm{a}, \mathrm{\jmath}, \mathrm{o}, \mathrm{v}, \mathrm{u}]$, asshown in Table 1.

Table1: Assamese surface vowels

\begin{tabular}{|l|l|l|l|}
\hline & Front & Back & \\
\hline High & i & u & +ATR \\
\hline & & u & -ATR \\
\hline Mid & e & o & +ATR \\
\hline & $\varepsilon$ & $o$ & -ATR \\
\hline Low & & a & -ATR \\
\hline
\end{tabular}

The two high vowels [i] and [u] are pronounced with an advanced tongue root (indicated in phonological representations by the feature [+ATR]) as are the mid vowels [e] and [o]. The mid vowels $[\varepsilon]$ and $[0]$ are slightly lower than [e] and [o], and are not realized with an advanced tongue root (i.e. they are specified as [-ATR]). Though it may appear from this table that all eight vowels appear contrastively, there are constraints on the distribution of [e] and [o] - they can only occur under circumstances of vowel harmony (and in some lexically specified exceptional circumstances, such as borrowed words and loan words; see Mahanta 2008). [a]is the lowest vowel in the inventory, and apart from being a low vowel,[a] is also back and [-ATR]. In Section 4.2 we show how [e] and [o] may also have constraints against occurring together.

Thus, the obvious distinctions are along the parameters of height, [ATR], and backness (except for[a] and [u], as they do not have front counterparts), but harmonic alternations are restricted to the [ATR] set of vowels. This system of eight vowels contrasts the [+ATR] set ([i], [u], [e], [o]) with the [ATR] set ([v], $[\varepsilon],[0],[a])$. These distinctions with the feature values for $[$ ATR $]$ are distributed as below:

$$
\begin{aligned}
& \text { [+ATR }] \text { and [-ATR }] \text { distinctions } \\
& \text { [+ATR] } \\
& \text { i u } \\
& \text { e } \mathrm{o}
\end{aligned}
$$

The featural distribution system above shows that there is a contrast in terms of the feature [ATR], but the contrast is less than perfect: There is a gap reflected in the absence of a [-ATR] high front vowel. A very common gap in seven vowel systems like Yoruba is the absence of any [-ATR] high vowels. Assamese is therefore atypical for seven or nine vowel systems in ATR harmony languages (cf. Stewart 1967, 1971) where gaps are encountered with respect to the low vowel /a/ and [-ATR] high vowels.

The existence of vowel harmony as a regular synchronic process is evident from the distribution of vowels in the language. A thorough investigation has revealed that even in the underived part of the vocabulary, the underlying [-ATR] vowels $/ \varepsilon /, / \mathrm{J} /$, and $/ \mho /$ are not attested in conjunction with the $[+\mathrm{ATR}+\mathrm{High}]$ vowels $/ \mathrm{i} /$ and $/ \mathrm{u} /$ to their right. Assamese imposes severe restrictions on the occurrence of the features [-ATR] and [+ATR] consecutively, in derived as well as underived domains. Although the absence of $* / \varepsilon \ldots \mathrm{i} /, * / \varepsilon \ldots \mathrm{u} /, * / \mathrm{o} \ldots \mathrm{i} /, * / \mathrm{o} \ldots \mathrm{u} /, * / \mho \ldots \mathrm{i} /$, and $* / u \ldots \mathrm{u} /$ sequences demonstrates that $/ \varepsilon /$, $/ \mathrm{J} /$, and $/ \mathrm{u} /$ do not surface in such sequences, it is the harmonic alternations in morphologically complex words that demonstrate that these sounds change.

(2) Examples of harmony in underived words

$\begin{array}{lll} & \text { Word } & \text { Gloss } \\ \text { a. zelepi } & \text { 'sweet' } \\ \text { b. tekeli } & \text { 'earthen pot' } \\ \text { c. leteku } & \text { 'berry' } \\ \text { d. keseru } & \text { 'tree' } \\ \text { e. bogoli } & \text { 'crane' }\end{array}$

As the examples below demonstrate, in the absence of the /i/ and / $\mathrm{u} /$ triggers, [-ATR] vowels can combine together. 
(3) $[-$ ATR $]$ vowels in the absence of $[+$ ATR $]$ vowels

$\begin{array}{lll} & \text { Word } & \text { Gloss } \\ \text { a. beson } & \text { 'powdered pulse' } \\ \text { b. } & \text { gorom } & \text { 'hot' } \\ \text { c. beleg } & \text { 'different' } \\ \text { d. poxek } & \text { 'week' } \\ \text { e. zukar } & \text { 'shake' }\end{array}$

These distributional characteristics lead us to surmise that the underlying vowel inventory of Assamese consists of six vowels, /i/, /u/, / / /, / /, / / and /a/, in its stem phonology. Whereas /i/ and /u/ never alternate, $/ \varepsilon /$ and $/ \mathrm{o} /$ alternate with $[\mathrm{e}]$ and $[\mathrm{o}]$, respectively, when followed by $/ \mathrm{i} / \mathrm{and} / \mathrm{u} /$; but $/ \mathrm{v} /$ exists in the underlying inventory as one of the [-ATR] vowels. The [+ATR] mid vowels [e] and [o] never surface by themselves in the absence of following high [+ATR] vowels./a/ is not subject to alternation and appears unaltered even in the presence of succeeding [+ATR] vowels /i/ and /u/.

In Assamese, all vowels in a word may be either [-ATR] or [+ATR], depending on the presence of a following [+High+ATR] vowel, which triggers the preceding [-ATR] mid vowels to agree with its [+ATR] value. The examples in (4) and (5) show that whenever $/ \mathrm{i} /$ and $/ \mathrm{u} / \mathrm{are}$ in a suffix, they consistently impose changes on the [ATR] specifications of the vowels $/ \varepsilon /, / \mathrm{J} /$ and $/ \mathrm{u} /$ in the stem/root.

(4) Monosyllabic roots - the presence of a high vowel in the suffix results in vowel

\begin{tabular}{|c|c|c|c|c|}
\hline $\begin{array}{l}\text { Root } \\
\text { box }\end{array}$ & $\begin{array}{l}\text { Gloss } \\
\text { 'settle' }\end{array}$ & $\begin{array}{l}\text { Suffix } \\
o+\mathrm{ti}\end{array}$ & $\begin{array}{l}\text { Derivation } \\
\text { boxoti }\end{array}$ & $\begin{array}{l}\text { Gloss } \\
\text { 'settlement' }\end{array}$ \\
\hline mor & 'die' & $o+t i$ & moroti & 'cursed to die' \\
\hline xeh & 'last' & $o+t i+j a$ & xehotija & 'recent' \\
\hline d. $\quad l \varepsilon \mathrm{k}^{\mathrm{h}}$ & 'write' & $\mathrm{i}+\mathrm{ka}$ & lek ${ }^{\mathrm{h}} \mathrm{ika}$ & 'writer' \\
\hline $\mathrm{d}^{\mathrm{h}} \mathrm{ul}$ & 'drum' & ija & $\mathrm{d}^{\mathrm{h}} \mathrm{ulija}$ & 'drummer' \\
\hline gul & 'mix’ & $\mathrm{i}$ & guli & 'to mix’ \\
\hline $\mathrm{pet}$ & ‘belly’ & $\mathrm{u}$ & petu & 'pot bellied' \\
\hline roy & 'colour' & $o+$ su+uwa & rojosuwa & 'colourful' \\
\hline
\end{tabular}

(5) Harmony when suffixes are attached to bisyllabic roots ${ }^{2}$

\begin{tabular}{|c|c|c|c|c|c|}
\hline & Root & Gloss & Suffix & Derivation & Gloss \\
\hline a. & bosor & 'year' & $\mathrm{i}$ & bosori & 'yearly' \\
\hline b. & $\mathrm{b}^{\mathrm{h}}$ okst & 'votary of a deity' & $\mathrm{i}$ & $\mathrm{b}^{\mathrm{h}}$ okoti & 'devotion' \\
\hline c. & $\mathrm{p}^{\mathrm{h}} \varepsilon \mathrm{d} \varepsilon \mathrm{la}$ & 'ugly’ (MASCULINE) & $\mathrm{i}$ & $\mathrm{p}^{\mathrm{h}}$ edeli & 'ugly' (FEMININE) \\
\hline d. & gerela & 'fat' (MASCULINE) & $\mathrm{i}$ & gereli & 'fat' (FEMININE) \\
\hline e. & $\mathrm{b}^{\mathrm{h}}$ \&kola & 'big frog' & $\mathrm{i}$ & $\mathrm{b}^{\mathrm{h}}$ ekuli & 'small frog' \\
\hline f. & $\mathrm{t}^{\mathrm{h}}$ opuka & 'plump' (masculine) & $\mathrm{i}$ & $\mathrm{t}^{\mathrm{h}}$ upuki & 'plump' (feminine) \\
\hline g. & butola & 'pick' & $\mathrm{i}$ & butoli & 'pick' (infinitive) \\
\hline h. & upor & 'above' & $\mathrm{i}$ & upori & 'over and above' \\
\hline i. & utol & 'boil' & $\mathrm{i}$ & utoli & 'boiling' (infinitive) \\
\hline $\mathrm{j}$. & pisol & 'slippery' & $\mathrm{i}$ & pisoli & ‘slip' (infinitive) \\
\hline
\end{tabular}

We can now summarize these observations by stating that the vowels $/ \varepsilon /, / \supset /$ and $/ u /$ systematically change to [e], [o] and [u] (respectively), in all stem-suffix environments, in the presence of a triggering high vowel in the suffix. The phonological grammar of the language is such that the native vocabulary does not contain any forms with [e] and [o] only (with the exception of loan words; see Mahanta 2008).

\footnotetext{
${ }^{1}$ Note the overabundance of suffixes bearing the vowel /i/. It is a fact of the language that /i/ suffixes far outnumber suffixes with the trigger $/ \mathrm{u} /$, but whenever $/ \mathrm{u} /$ appears it unfailingly triggers vowel harmony.

${ }^{2}$ Some combinations, like $/ \mathrm{s} /+/ \varepsilon /$, were found not to exist in the native vocabulary.
} 
The examples below show that the presence of a [-ATR] suffix does not lead to the alteration of the values of the preceding vowels.

\begin{tabular}{|c|c|c|c|c|c|}
\hline 6) & \multicolumn{5}{|c|}{ No alternation when $[-\mathrm{ATR}]$ suffixes are attached to roots } \\
\hline & Root & Gloss & Suffix & Derivation & Gloss \\
\hline a. & $b^{h} u t$ & 'ghost' & $\varepsilon$ & $b^{h} u t \varepsilon$ & 'ghost' (ERGATIVE) \\
\hline b. & gorom & 'hot' & ot & goromot & 'heat' (ACCUSATIVE) \\
\hline c. & beleg & 'different' & $\varepsilon$ & belege & 'differently’ \\
\hline d. & poxek & 'week' & ot & poxekot & ‘week'(ERGATIVE) \\
\hline e. & $\mathrm{p}^{\mathrm{h}} \mathrm{ur}$ & 'travel/roam' & $U$ & $\mathrm{p}^{\mathrm{h}} \mathrm{urv}$ & 'travel/roam'(FIRST PERSON PRESENT) \\
\hline f. & kin & 'buy' & $\varepsilon$ & kine & ‘buy'(ERGATIVE) \\
\hline
\end{tabular}

The examples below show how the prefixal vowels /o-/ and / $\varepsilon-/$ change their feature value to [+ATR] in an environment where there is $\mathrm{a} / \mathrm{i} / \mathrm{or} \mathrm{a} / \mathrm{u} /$ on the right side of the morphological word:

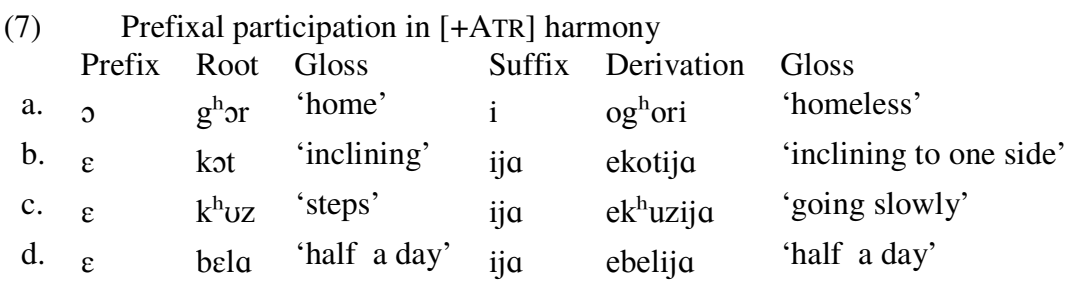

The examples above show how the prefixal vowels /o-/ and / $\varepsilon$-/change their feature values to [+ATR] in an environment where there is $/ \mathrm{i} /$ or $/ \mathrm{u} /$ on the right side of the morphological word. The data provided thus farprovide sufficient evidence that Assamese harmony is regressive, and is always triggered by an immediately following /i/ or / $\mathrm{d}$, regardless of the morphological affiliation of the trigger or the target. This harmony constraint produces the alternations $/ \varepsilon / \rightarrow[\mathrm{e}], / \mathrm{\rho} / \rightarrow[\mathrm{o}]$, and $/ \mathrm{v} / \rightarrow[\mathrm{u}]$, where the outputs [e] and [o] are purely allophonic, but [u] is not. Assamese vowel harmony is typically wordbased, excluding compounded words and larger morpho-syntactic domains. Vowel harmony in Assamese is a leftward process, and there are no morphologically significant positions that either trigger or target it.

This paper, however, concerns itself to a large extent with certain exceptionalities that stray from the regular harmony pattern of Assamese. Of utmost importance in understanding these exceptional processes is the fact that the generally opaque vowel /a/in words like /kopahi/ 'made of cotton' and /gozali/ 'sprout' (more examples in Section 1.3) is raised as a result of the presence of the vowels /i/ and / $\mathrm{u} /$ contributed by the morphemes /-ija/ and /-uwa/. /a/-raising does not occur when /a/ is not adjacent to the triggering vowel. Some representative examples are below:

(8) /a/ does not change when it is not adjacent to the triggering vowel

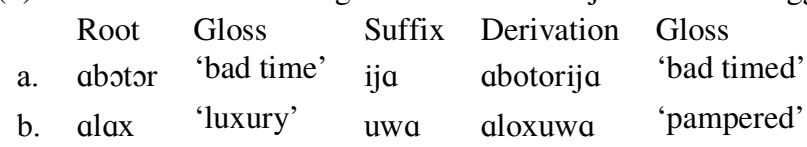

It is argued in Section 2.1 that /-ija/ and /-uwa/are exceptional triggers, and need to be analyzed with a lexical indexation approach, in which a convention of locality has to be followed. In Sections2.2and 2.3 we will discuss the typological implications of this pattern to show that exceptional harmony is the only environment that requires a locality convention. The entirety of Section 4 discusses the pattern where a front harmony pattern emerges after/a/ raising in words like /عlah/+/uwa/ $\rightarrow$ [elehuwa] 'lazy'. I argue that this phonologically derived environment has to be analyzed with the help of a highly ranked positional markedness constraint and a LICENSE constraint leading to the emergence of the unmarked pattern.

1.2Analysis of vowel harmony in Assamese

In this paper, regressive iterative directionality is shown to be the result of the sequential markedness constraint $*[-\mathrm{ATR}][+\mathrm{ATR}]$. This constraint can be violated only when the featural composition of the 
vowels in question are in a specific marked sequence. Therefore, a constraint $*[-\mathrm{F}][+\mathrm{F}]$ is not violated by $[-\mathrm{F}][-\mathrm{F}],[+\mathrm{F}][+\mathrm{F}]$ or by $[+\mathrm{F}][-\mathrm{F}]$ sequences. The candidates that are in the sequential order $[-\mathrm{F}][-$ $\mathrm{F}]$ and $[+\mathrm{F}][-\mathrm{F}]$ vacuously satisfy the constraint because they do not provide the right context for its application. These sequential markedness constraints can also be seen as sub-components of the AGREE family of constraints (Bakovic 2000; Beckman 1998; Butska 1998; Lombardi 1996ab, 1999). ${ }^{3}$

AGREE[F]

Adjacent segments must have the same $[\alpha \mathrm{F}]$ value of the relevant feature.

However, there are some important differences between AGREE and sequential markedness. An agreement constraint is left-right symmetrical and is also a contextual neutralization constraint.As a result of this symmetry, AGREE[F] can be satisfied by two candidates: (a) a string where all adjacent segments are $[-\mathrm{F}]$, and (b) a string of $[+\mathrm{F}]$ adjacent segments. So in order to satisfy AGREE in an input where two adjacent segments have opposing values for the feature $[F]$, the outputs may be such that either the first segment of the pair may agree with second, or the second may agree with the first. AGREE[F] is equally satisfied with both of these outputs, and the onus of selecting between the two falls on other markedness and faithfulness constraints. For example, if the input candidate were [ATR][+ATR][-ATR] in a regressive [+ATR] vowel harmony system, AGREE would favor total agreement. However, the directionality of the regressive vowel harmony system would demand regressive agreement, i.e., a sequence of $[+\mathrm{ATR}][+\mathrm{ATR}][-\mathrm{ATR}]$ vocalic features. In this scenario, AGREE alone would predict an incorrect result, favoring outputs which conform to total assimilation, i.e., either $[-\mathrm{ATR}][-\mathrm{ATR}][-\mathrm{ATR}]$ or $[+\mathrm{ATR}][+\mathrm{ATR}][+\mathrm{ATR}]$.

(10) AGREE[F]and directional spreading

\begin{tabular}{|l||c|c|c|}
\hline$[-\mathrm{ATR}][+\mathrm{ATR}][-\mathrm{ATR}]$ & AGREE[ATR] & IDENT[+ATR] & IDENT[-ATR] \\
\hline \hline a. $[-\mathrm{ATR}][+\mathrm{ATR}][-\mathrm{ATR}]$ & $* !$ & & \\
\hline b. ${ }^{4}[+\mathrm{ATR}][+\mathrm{ATR}][-\mathrm{ATR}]$ & $* !$ & & $*$ \\
\hline c. $\boldsymbol{\sigma}^{\mathrm{*}}[+\mathrm{ATR}][+\mathrm{ATR}][+\mathrm{ATR}]$ & & & $* *$ \\
\hline d. $[-\mathrm{ATR}][-\mathrm{ATR}][-\mathrm{ATR}]$ & & $* !$ & \\
\hline
\end{tabular}

The tableau in (10) shows that, in the absence of any reliable morphological or prosodic motivation, AGREE by itself does not lead to regressive or progressive directionality. In the persistently regressive harmony of Assamese there is no substantive positional relevance of the trigger, therefore other theoretical devices like positional faithfulness and local conjunction also prove to be redundant. As such, in the proposed analysis, I proceed to disentangle the behavior of AGREE from its inherently asymmetric nature, and modify it into a more specific constraint which identifies a specific marked sequence of features. In the tableau above, AGREE[F] assigns a violation mark to the desired output candidate $(10 \mathrm{~b})$, but if a sequential markedness constraint $*[-\mathrm{F}][+\mathrm{F}]$ had been in its place, this violation could have been avoided. Consequently, if AGREE[F] is broken up into the following sub-constraints, then Universal Grammar must choose one of the specific markedness constraints:

Sequential markedness constraints

$*[+\mathrm{F}][-\mathrm{F}]$ : Assign a violation mark to $[-\mathrm{F}]$ segments preceded by $[+\mathrm{F}]$ segments.

$*[-\mathrm{F}][+\mathrm{F}]$ : Assign a violation mark to $[+\mathrm{F}]$ segments preceded by $[-\mathrm{F}]$ segments

In the context of Assamese, where a [-ATR] feature is always neutralized by a following [+ATR] feature, the relevant markedness constraint is justifiably *[-ATR][+ATR]. Along with this harmony-driving markedness constraint, there are other relevant faithfulness and markedness constraints which allow us to capture basic harmony in Assamese. I define the relevant constraints below:

IDENT[High]

A segment in the output and its correspondent in the input must have identical specifications for [High].

\footnotetext{
${ }^{3}$ The other possibility is the inclusion of Alignment constraints, but Alignment in a regressive system does not provide us with an adequate explanation as there is no linguistically significant morphological or prosodic edge which can be used to designate edge alignment. It can also potentially result in candidates which are aligned to the wrong edge (Hansson 2001).

${ }^{4}$ Throughout this paper, the symbol is used to indicate the candidate which is the attested form, but fails to be the optimal candidate in the tableau. The symbol indicates the candidate which is not the attested form, but which is the winner as a result of the constraint hierarchy.
} 
IDENT[High] is never violated in Assamese. [-High] or [+High] vowels never alter their height values to satisfy any harmony condition. Hence, IDENT[High] is one of the undominated constraints in the language.

$*[+$ High - ATR - Back $]$

Assign a violation mark to vowels with the feature values [-ATR], [+High], and [-Back].

The constraint $*[+$ High - ATR - Back $]$ is also undominated, and this featural markedness constraint bans any instance of $/ \mathrm{I} /$ in order to satisfy regressive $[\mathrm{ATR}]$ harmony.

$*[-\mathrm{ATR}][+\mathrm{ATR}]$

Assign a violation mark to a [-ATR] segment followed by a [+ATR] segment.

This is the harmony-driving constraint which bans sequences of [-ATR][+ATR]. This constraint must be ranked below the two undominated constraints in (12) and (13).

\section{IDENT[ATR]}

Assign a violation mark to a segment in the output if its correspondent in the input has adifferent specification for [ATR].

The basic harmony profile of Assamese is obtained by the ranking of *[-ATR][+ATR] »IDENT[ATR], where [-ATR] values are neutralized in order to satisfy the markedness requirement demanded by the constraint which seeks avoidance of $[-\mathrm{ATR}][+\mathrm{ATR}]$ sequences, resulting in regressive [ATR] vowel harmony. Using the constraints above, we can show the evaluation of an input form where a [-ATR] vowel is followed by a [+ATR + High] vowel.

(16) Vowel harmony in Assamese

\begin{tabular}{|l||c|c|c|}
\hline$/$ kor/+/i/('do' INF) & [DENT[High] & $*[-$ ATR][+ATR] & IDENT[ATR] \\
\hline \hline a. kori & & $* !$ & \\
\hline b. ${ }^{\circ}$ kori & & & $*$ \\
\hline c. kuri & $* !$ & & $*$ \\
\hline
\end{tabular}

As such, the constraints IDENT[High] and $*[-$ ATR + High - Back $]$ are undominated in Assamese. The tableau above shows that the harmony-driving constraint * [-ATR][+ATR] is ranked above IDENT[ATR], leading to the alteration of [ATR] values only. The constraint $*[-\mathrm{ATR}][+\mathrm{ATR}]$ plays a crucial role in prohibiting output sequences with an [ATR] mismatch in their feature specifications. This tableau assumes that there is no ranking between $*[-\mathrm{ATR}][+\mathrm{ATR}]$ and the two undominated constraints, IDENT[High] and *[-ATR +High -Back]. This is only a partial analysis of harmony in Assamese, as the full harmony facts have not been laid out as of yet. Once all the data are in place, we shall see that a ranking between $*[-\mathrm{ATR}][+\mathrm{ATR}]$ and the undominated constraints is required because of blocking by /a/ (see (23)).

In the absence of a harmony trigger to the right, only [-ATR] mid vowels can occur. This can be accounted for by the articulatorily grounded constraint $*[-$ High + ATR $]$. Following Archangeli and Pulleyblank's (1994) grounding conditions ${ }^{5}$, I propose the feature co-occurrence constraint defined below, which becomes relevant when mid vowels are present in the input.

$*[-$ High + ATR $]$

Assign a violation mark to a [+ATR] feature value in [-High] vowels.

This constraint will play a role in the evaluation of words that have only mid vowels. In order to ensure that this constraint restricts the inventory, let us consider inputs where all vowels are [-High +ATR]. A highly ranked constraint $*[-\mathrm{ATR}][+\mathrm{ATR}]$ would try to enforce agreement, but $*[-$ High + ATR $]$ would prevent multiple occurrences of [e] and [o].

(18) Input: /beson/, for the surface form [beson] in (3a)

\begin{tabular}{|l||c|c|c|}
\hline$/$ beson/ & $*[-\mathrm{ATR}][+\mathrm{ATR}]$ & $*[-\mathrm{High}+\mathrm{ATR}]$ & IDENT[ATR $]$ \\
\hline \hline a. beson & & $* * !$ & \\
\hline
\end{tabular}

\footnotetext{
${ }^{5}$ The grounding conditions in Archangeli and Pulleyblank's (1994) work pertain to the fact that tongue root advancement ([ATR]) and tongue body raising ([High]) are articulatorily synchronized, while tongue root advancement ([ATR]) is detrimental to the production of tongue body lowering ([Low]).
} 


\begin{tabular}{|l||c|c|c|}
\hline b. beson & $* !$ & $*$ & $*$ \\
\hline c. ${ }^{\circ}$ beson & & & $* *$ \\
\hline d. beson & & $* !$ & $*$ \\
\hline
\end{tabular}

The tableau above in (18) demonstrates that while the constraint *[-High +ATR] prohibits output occurrences of $[\mathrm{e}]$ and $[\mathrm{o}]$, the constraint $*[-\mathrm{ATR}][+\mathrm{ATR}]$ penalizes disharmonic sequences. Tableau(18)shows that it is important to have both [ATR]agreement and mid vowels.

We have already discussed inputs with a mid vowel / / and a triggering vowel /i/ in (16). We have not yet considered candidates lacking either a $/ \varepsilon / \rightarrow[\mathrm{e}]$ or a $/ \mathrm{J} \rightarrow[\mathrm{o}]$ alternation due to the regressive nature of harmony in Assamese. The occurrence of forms like /kine/ 'buy'(ERGATIVE), which we will discuss shortly, involves feature co-occurrence restrictions along with sequential markedness restrictions, because [-High + ATR] vowels do not occur in positions which are not followed by [+High + ATR] vowels. Therefore, the surfacing of [kine] vs. *[kine] can be attributed to a feature cooccurrence constraint in the context of a prominence restriction which prevents occurrences of [-High + ATR] in marked positions.

(19) $*[-$ High + ATR $]$ restricts [e] and [o] together with *[-ATR $][+$ ATR $]$

\begin{tabular}{|c|c|c|c|c|c|}
\hline$/ \mathrm{kin} /+/ \varepsilon /$ & IDENT[High] & $*[-\mathrm{ATR}+\mathrm{High}-\mathrm{Back}]$ & *[-ATR $][+\mathrm{ATR}]$ & $*[-$ High +ATR $]$ & IDENT[ATR] \\
\hline a. $\mathrm{kin} \varepsilon$ & & & $\vdots$ & & \\
\hline b. kine & & & 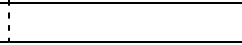 & $* !$ & * \\
\hline c. kine & & $* !$ & $\vdots$ & $*$ & $* *$ \\
\hline
\end{tabular}

The tableau in (19) shows that the constraint *[-High +ATR] clearly restricts the inventory for all unattested cases like *[kine] but cannot exclude real occurrences like [kori]. The tableau below in (20) shows that the incorporation of $*[-$ High + ATR $]$ does not prohibit the selection of the correct output [kori] with harmony.

(20) [kori] after the incorporation of $*[-$ High + ATR $]$

\begin{tabular}{|l||c|c|c|c|}
\hline$/ \mathrm{kor} /+\mathrm{i} /$ & $*[-\mathrm{ATR}+\mathrm{High}-\mathrm{Back}]$ & $*[-\mathrm{ATR}][+\mathrm{ATR}]$ & $*[-\mathrm{High}+\mathrm{ATR}]$ & IDENT[ATR] \\
\hline \hline a. kri & & $* !$ & & \\
\hline b. ${ }^{*}$ kori & & & $*$ & $*$ \\
\hline c. korI & $* !$ & & $*$ & $* *$ \\
\hline
\end{tabular}

The ranking of the constraint $*[-\mathrm{ATR}][+\mathrm{ATR}]$ above the constraint $*[-$ High + ATR $]$ is justified in the tableau above, where vowel harmony is attested. * $[-$ High + ATR $]$ is violated by the selected candidate (20b), but that is not a fatal violation. Both the competing candidates (20) and (20) violate the constraint $*[-$ High + ATR] by having the vowel [o]. Among the losing candidates, while (20a) incurs a $*[-\mathrm{ATR}][+\mathrm{ATR}]$ violation by not undergoing harmony, $(20 \mathrm{c})$ violates $*[-\mathrm{ATR}+\mathrm{High}-\mathrm{Back}]$ by changing the [+High + ATR] value of the input's high vowel to [-ATR].

\subsection{Blocking by /a/ and /a/-raising}

Thus far, we have concentrated on the description and analysis of vowel harmony in Assamese, without probing the segments or features which can check the percolation of uninhibited regressive harmony. While nasals and consonant clusters have also been shown to block harmony in Assamese (see Mahanta 2008), we will exclusively concern ourselves with blocking by the segment /a/. Whereas / $/$ / alternates with $[\mathrm{e}], / \mathrm{s} /$ alternates with $[\mathrm{o}]$, and / $/$ / alternates with $[\mathrm{u}], / \mathrm{a} /$ is a non-alternating vowel in the inventory. Therefore, /a/ behaves as a phonologically opaque vowel. ${ }^{6}$

In the analysis presented here, /a/ is protected by the faithfulness constraint IDENT[Low], as /a/'s involvement in harmony would also result in the violation of $*[+\mathrm{ATR}+\mathrm{Low}]$, an undominated constraint, because low [+ATR] vowels are absent from the surface inventory.

${ }^{6}$ This has been reported for [ATR] harmony in Hall et al. (1980), mostly in West African languages (e.g. Wolof, Fula, Diola Fogny). In these systems, the organizing principle is such that [+ATR] vowels are dominant and [-ATR] vowels are recessive, so that opaque vowels can block the harmony propagated by the triggering [+ATR] vowel and start their own harmony domain. 
(21) Assamese trisyllables with medial /a/ and final /i/

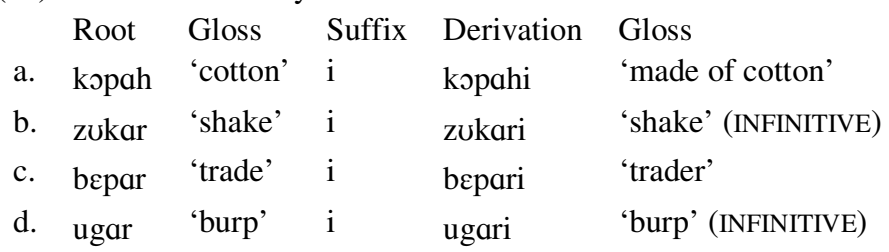

The examples in (21) represent words in which /a/ occurs word-medially and there is no agreement with the [+ATR] value of the triggering suffixal vowel. Instead, the leftmost vowel is [-ATR] and has not been influenced by the [+ATR] vowel in the right periphery. ${ }^{7}$ There are also various suffixes with /a/ that result in opacity. Below are some examples:

(22) /a/-initial suffixes block harmony

\begin{tabular}{|c|c|c|c|c|}
\hline $\begin{aligned} & \text { Root } \\
\text { a. } & 1 \varepsilon \mathrm{k}^{\mathrm{h}}\end{aligned}$ & $\begin{array}{l}\text { Gloss } \\
\text { 'write' }\end{array}$ & $\begin{array}{l}\text { Suffix } \\
\text { aru }\end{array}$ & $\begin{array}{l}\text { Derivation } \\
1 \varepsilon \mathrm{k}^{\mathrm{h}} \text { aru }\end{array}$ & $\begin{array}{l}\text { Gloss } \\
\text { 'writer' }\end{array}$ \\
\hline goz & 'grow' & ali & gozali & 'sprout' \\
\hline zun & 'moon' & ali & zunali & 'moonlit' \\
\hline rup & 'silver' & ali & rupali & ‘silvery’ \\
\hline
\end{tabular}

The tableau in (23) below shows how IDENT[Low] is responsible for blocking harmony:

(23) Input /kspahi/:/a/ remains unaltered in the presence of a following trigger

\begin{tabular}{|l||c:c|c|c|c|}
\hline$/ \mathrm{kspah} /+\mathrm{i} /$ & $*[+\mathrm{ATR}+\mathrm{Low}]$ & IDENT[Low] & $*[-\mathrm{ATR}][+\mathrm{ATR}]$ & $*[-$ High + ATR $]$ & IDENT[ATR] \\
\hline \hline a. ${ }^{*} \mathrm{kopahi}$ & & & $*$ & & \\
\hline b. kopohi & & $* !$ & & $* *$ & $* *$ \\
\hline c. kopæhi & $* !$ & & & $* *$ & $* *$ \\
\hline
\end{tabular}

The opacity of /a/ to the harmony process is accounted for by high-ranked IDENT[Low] and *[+ATR +Low]. These constraints are ranked higher than the harmony driving constraint *[-ATR][+ATR]. Therefore, the candidate in (23a), which does not undergo any /a/ alteration, is the winning candidate.

\subsection{Regular harmony triggered by /-ija/ and /-uwa/}

Thus far we have seen that the spectrum of regularity in the process of vowel harmony in Assamese encompasses harmonic effects of the following nature: The basic harmony pattern is that of regressive [+ATR] harmony, for any [-ATR] vowel except /a/. Although harmony is iterative, the harmony trigger is always local, such that all the [-ATR] vowels in the inventory (except for /a/) become [+ATR] when the following vowel is [+ATR]. Furthermore, we have seen that the harmonizing vowel retains its underlying [Back] value.

Before going into the details of exceptionality, I will draw examples from the regular morphology to show the operation of vowel harmony in a regularly derived environment domain involving the suffixes /-ija/ and /-uwa/. In examples (24) and (25) below, the [High] vowels in the suffixes trigger [+ATR] harmony in the preceding root/stem.

(24) Monosyllabic roots and regular vowel harmony triggered by /-ija/ and /-uwa/

$\begin{array}{llllll} & \text { Root } & \text { Gloss } & \text { Suffix } & \text { Derived } & \text { Gloss } \\ \text { a. } & \text { mer } & \text { 'wind' } & \text { uwa } & \text { meruwa } & \text { 'wind'(CAUSATIVE) } \\ \text { b. } & \text { sor } & \text { 'slap' } & \text { ija } & \text { sorija } & \text { 'to slap' } \\ \text { c. } & \text { d }^{\text {h }} \mathrm{ll} & \text { 'drum' } & \text { ija } & \mathrm{d}^{\mathrm{h}} \text { ulija } & \text { 'drummer' }\end{array}$

\footnotetext{
${ }^{7}$ There is no evidence that the second vowel harmonizes in /CaCVC/ sequences. As has been exhaustively discussed, [e] and [o] are allophonic in Assamese and should occur only in harmonic environments (i.e. in the presence of /i/ and / $\mathrm{u} /$ to the right). In the absence of underlying /e/ and /o/, we cannot claim that the resulting $[\varepsilon]$ and $[0]$ appear as a result of the preceding /a/.
} 
d. tel 'oil' ija telija 'oily'

(25) Regular vowel harmony in bisyllabic stems

Root Gloss Suffix Derived Gloss

a. boyox 'age' ija boyoxija 'aged'

b. tolot 'below' ija tolotija 'subordinate'

c. gubor 'dung' uwa guboruwa 'kind of beetle found in dung'

The examples above show that there is ample evidence that the adjectival suffixes /-ija/ and /-uwa/ participate in regular [ATR] harmony when the preceding [-ATR] vowels are $/ \varepsilon /, / \supset /$, and $/ \mho /$.

With this background we can now engage in the description and analysis of some of the vagaries (i.e. exceptional patterns) of vowel harmony in Assamese. In Section 2, we begin with monosyllabic roots containing /a/, followed by bisyllabic roots with two consecutive /a/'s. In Section 2.1 we present an analysis based on lexical exceptions and subsequently in Section 2.3 we present a broad overview of the typology of exceptions in vowel harmony.

\section{2 /a/-raising: Local exceptional triggering}

The morphemes /-ija/ and /-uwa/ trigger [ATR] harmony in accordance with the harmony characteristics outlined in Section 1.4. Section 1.4 however, abstains from demonstrating any phonological opacity of /a/ in the presence of /-ija/ and /-uwa/, precisely because this is the environment in which/a/ loses its static quality as far as [ATR] harmony is concerned. Under normal circumstances, the vowel /a/, whether in the prefix, suffix or stem position, invariably behaves phonologically opaquely. If in certain circumstances/a/ appears to contravene this normal behavior and is able to undergo vowel harmony, then that behavior has to be characterized as exceptional and the characteristics of such exceptional participation in harmony need to be examined in detail. The [-ATR +Low] vowel /a/ in Assamese undergoes raising to the [+ATR] vowels [e] and [o] in order to participate in [ATR] harmony, but only when it is in the environment of the previously mentioned triggering morphemes/-ija/ and/-uwa/. In this section we will only deal with those environments where /a/ alternates with [o]. This pattern will be elaborated in Section 4, where /a/ sometimes undergoes height harmony and fronting to alternate with[e]. The data below show that /a/-raising alone appears in words of the following configuration:

Schema of /a/-raising to /o/

a. $\quad(\mathrm{C}) \mathrm{iCa}+\mathrm{ija} \rightarrow(\mathrm{C}) \mathrm{iCo}+\mathrm{ija}$

b. $\quad(\mathrm{C}) \mathrm{aCa}+\mathrm{ija} \rightarrow(\mathrm{C}) \mathrm{aCo}+\mathrm{ija}$

In words containing the vowel sequences above, the locality of the process always results in words where only the /a/ adjacent to the triggering vowel undergoes raising to [o], resulting in words of the type [(C)VCoCija]. /a/-raising occurs when the two affixes /-ija/ and /-uwa/ trigger harmony in morphemes containing /a/ ${ }^{8}$ As a result of this raising, /a/ raises to [o] under exceptional morphological triggering in these environments, but remains inalterable in the regular phonology. ${ }^{9}$ In monosyllabic stems, /a/ always adapts itself to [o] when followed by /-ija/ or /-uwa/.

\footnotetext{
${ }^{8}$ The origin of the suffix /-iya/ can be traced to Sanskrit /-i+k+a/ and /-uwa/ to the Sanskrit suffix /-u+k+a/ which implies loveableness, affection, scornfulness, etc. of the object implicated. In some instances of Standard Colloquial Bengali /ia/ contracts to /e/ and /ua/ to /o/. (Both are counterparts of /-iya/ and/-uwa/ respectively.) (Tunga 1995)

${ }^{9}$ See Bakovic (2000) for an analysis of 're-pairing' in Maasai, Turkana and Turkish. In the specific case of Turkish, prospective $[\mathfrak{r} \gamma]$ are prohibited by re-pairing the mid [-Low -Back] with the [+Low +Back] vowel [a]. Although this is a characteristic of the entire phonology of Turkish, in Assamese 'raising' is the result of harmony triggered only by the exceptional morphemes.
} 


\begin{tabular}{|c|c|c|c|c|}
\hline $\begin{array}{l}\text { Root } \\
\text { sal }\end{array}$ & $\begin{array}{l}\text { Gloss } \\
\text { 'roof' }\end{array}$ & $\begin{array}{l}\text { Suffix } \\
\text { iia }\end{array}$ & $\begin{array}{l}\text { Derivation } \\
\text { solija }\end{array}$ & $\begin{array}{l}\text { Gloss } \\
\text { 'roof-ed' }\end{array}$ \\
\hline dal & 'branch' & ija & dolija & 'branch-ed' \\
\hline$d^{h} \mathrm{ar}$ & 'debt' & uwa & $\mathrm{d}^{\mathrm{h}}$ oruwa & 'debtor' \\
\hline mar & 'beat'(VERB) & uwa & morija & 'beat' \\
\hline
\end{tabular}

The data below show that /a/-raising is restricted to the vowel adjacent to the triggering morpheme and there is no /a/-raising when /a/ is not adjacent to the triggering vowel:

(28) /a/ does not change when it is not adjacent to the triggering vowel

\begin{tabular}{|c|c|c|c|c|c|}
\hline a. & $\begin{array}{l}\text { Root } \\
\text { patol }\end{array}$ & $\begin{array}{l}\text { Gloss } \\
\text { 'light' }\end{array}$ & $\begin{array}{l}\text { Suffix } \\
\text { ija }\end{array}$ & $\begin{array}{l}\text { Derivation } \\
\text { patolija }\end{array}$ & $\begin{array}{l}\text { Gloss } \\
\text { 'lightly' }\end{array}$ \\
\hline b. & apod & 'danger' & $\mathrm{ija}$ & apodija & 'in danger' \\
\hline c. & abotor & 'bad time' & $\mathrm{ija}$ & abotorija & 'bad-timed' \\
\hline d. & alax & 'luxury’ & uwa & aloxuwa & 'pampered' \\
\hline e. & $\mathrm{ad}^{\mathrm{h}} \mathrm{a}$ & 'half' & uwa & $\operatorname{ad}^{\mathrm{h}}$ oruwa ${ }^{10}$ & 'halved' \\
\hline f. & misa & 'lie’ & $\mathrm{ija}$ & misolija & 'liar’ \\
\hline g. & $\mathrm{k}^{\mathrm{h}}$ itap & 'title' & ija & $\mathrm{k}^{\mathrm{h}}$ itopija & 'renowned/titled' \\
\hline h. & pixas & 'evil spirit' & ija & pixosija & 'ill-natured' \\
\hline
\end{tabular}

The examples (28a-c) have the segmental composition /CaCo.../ and harmony triggered by /-ija/ only affects the immediately preceding [-ATR] vowel /o/, but the non-adjacent /a/ does not undergo harmony. However, this is not different from the behavior of similar sequences when harmony is triggered by suffixes other than /-ija/ and/-uwa/, as they would all produce the same result. The local triggering behavior of /-ija/ and /-uwa/ is exemplified very clearly by the examples in (28d-e). In these cases, there are two instances of /a/, but only the vowel adjacent to the triggering vowel undergoes harmony. See the illustrations below for a more explicit illustration:

(29) Environments for /a/-raising to [o]

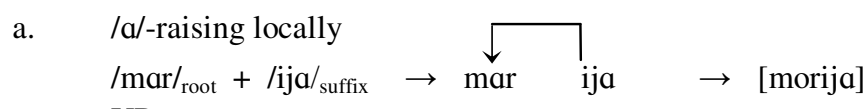

UR

b. No/a/-raising non-locally to /o/

Surface Form

$/ \mathrm{alax} /_{\text {root }}+/ \mathrm{uwa}_{\text {suffix }} \rightarrow \underset{\mathrm{aCaC}}{\mathrm{aC}} \underset{\text { uwa }}{\rightarrow \text { [aloxuwa] }}$

UR

Surface Form

(cf.*/oloxuwa/ */olaxuwa/)

/a/-raising triggered by /-ija/ and /-uwa/ ${ }^{11}$ violates IDENT[Low], but IDENT[Low] violations are as minimal as possible, because /a/-raising is restricted to the smallest possible domain.

The participation of only two morphemes /-ija/ and /-uwa/ in triggering exceptional realization of harmony can be characterized as morphologically induced harmony, which is obtained at the cost of flouting the highly ranked phonological constraint IDENT[Low] that prohibits any alteration of the

\footnotetext{
${ }^{10}$ Nothing much can be said about the choice between epenthetic /r/ and /1/ in (28e-f), apart from the fact that epenthesis presumably obtains for the sake of hiatus resolution. There are a few instances of epenthetic /1/ and /r/ in Assamese. See also (46).

11/-iya/ and /-uwa/ behave in a largely equivalent manner as far as their involvement in exceptional patterns is concerned. Therefore, any reference to only one of them implies reference to the other one as well.
} 
[+Low] vowel /a/. This violation leads to the harmonizing behavior of the normally opaque vowel /a/ in such a way that it changes to a vowel which is already present in the surface phonetic inventory. Exceptional triggering of the type discussed in this paper cannot be deemed to be the same as dominance (Aoki 1966; Chomsky and Halle 1968; Hall et al. 1974; Anderson 1980; Hall and Hall 1980; Dimmendaal 1983) in vowel harmony or other kinds of exceptionalities recorded in the literature. In Assamese, there are no instances of exceptional root or suffix morphemes which undergo harmony under special circumstances, nor are there cases where morphemes do not undergo harmony because they are opaque to the spreading process. The Assamese data are unique cases of exceptional triggers. However, they are only unique as far as exceptionality in vowel harmony is concerned. Such cases of local exceptionality are found in other morpheme-specific phonology as well. Pater (2006, 2009) shows that most of the problems tackled in morpheme-specific constraint ranking or cophonology, whose proponents include Anttila (1997, 2000, 2002), Inkelas (1998),Inkelas and Zoll (2005), Orgun (1996, 1998, 1999), and Orgun and Inkelas (2002), as well as faithfulness-only constraint indexation (Fukuzawa 1999; Itô and Mester 1999, 2001; Kraska-Szlenk 1997, 1999) theories can be analyzed in terms of constraint indexation of both markedness and faithfulness constraints. (See Section 3 for a critique of these approaches.) At the same time, however, the fact that exceptional triggering or blocking by morphemes is never an unbounded phenomenon is only predicted by lexically indexed constraints. Constraint indexation is of special relevance in this paper because the predicted 'local' behavior of morphemically indexed constraints is borne out in the exceptional data of Assamese. In the constraint indexation approach, morphemes that trigger a process are indexed for a lexically specific faithfulness or markedness constraint. It is assumed that these indexed constraints are cloned from already existing constraints, which are ranked lower in the hierarchy. In recent work, indexation of markedness constraints has also been shown to be operative in Dinka (Flack 2007) where an exceptional prosodic template imposes a fixed number of morae on vowels. Gouskova (2007) employs lexical indexation of markedness constraints to analyze reduplicative affixes in Tonkawa which vary in their syllabic shape following the requirements of non-templatic constraints. Ota (2004) has also shown that indexed markedness constraints could be required to analyze native and loan words in the Japanese lexicon, if certain aspects of learnability are taken into consideration.

We can consider the analysis for Finnish (Pater 2007, 2009), a language in which the stem-final low vowel /-a/ either deletes or is raised to /o/ under the influence of a following /-i-/. Examples like $/$ tavara $+\mathrm{i}+\mathrm{ssa} / \rightarrow$ [tavaroissa] 'thing' (PLURAL INESSIVE) and $/$ itara $+\mathrm{i}+\mathrm{ssa} / \rightarrow$ [itaroissa] 'stingy' (PLURAL INESSIVE) in Finnish show the locality of alternations in certain exceptional forms, given the environment in which /-a/ occurs. Pater addresses the problem of exceptionality in Finnish by introducing a locality convention which captures the locality encountered in Finnish.

$*[a i]_{\mathrm{L}}$

Assign a violation mark to any instance of $*$ [ai] that contains a phonological exponent of a morpheme specified as L.

The definition of the constraint above shows that the constraint is violated only when the specified string *[ai] occurs in the output. Without any further elaboration, I will simply repeat the (partial) tableau from Pater in order to provide an illustration:

(31) Lexicon: /-i-/L

\begin{tabular}{|l|l|l|l|}
\hline$/$ tavara- $\mathrm{i}_{\mathrm{L}}-\mathrm{ssa} /$ & $*[\mathrm{ai}]_{\mathrm{L}}$ & IDENT & $*[\mathrm{ai}]$ \\
\hline \hline a. tavaraissa & $* !$ & & $*$ \\
\hline b. ${ }^{*}$ tavaroissa & & $*$ & \\
\hline
\end{tabular}

In the tableau above, the faithfulness constraint IDENTconflicts with the markedness constraint *[ai]. The optimal candidate does not violate the indexed $*[a i]_{\mathrm{L}}$ but the competing $*$ [tavaraissa] runs afoul of the indexed $*[a i]_{\mathrm{L}}$ while preserving featural faithfulness. The constraint $*[a i]$ does not apply in an unbounded manner. It only applies to that part of the word where the suffixal /i/ also occurs.

Although discussion of indexation of faithfulness constraints is not within the scope of this paper, it is tacitly assumed that faithfulness indexation is involved in other exceptional phenomena which do not involve triggering. In exceptional triggering, locality effects will not be captured in a faithfulnessonly constraint indexation approach.

\subsection{Constraint indexation and morphologically conditioned exceptions in phonology}

Given the description of the pattern of alternation and /a/-raising in Section 2, I will now discuss the locality requirements which can be adequately addressed by the lexical indexation of the relevant constraints. 'Locality', or the application of a phonological process to a certain smallest possible 
domain, is of special relevance in this paper. Locality falls out from the locus of violation function, which has been implemented in recent OT grammars (Lubowicz 2005;McCarthy 2003a,b, 2005; McCarthy andWolf 2005; Riggle and Wilson 2004) by employing the notion of position of violation of a constraint. In the context of markedness constraints, this approach locates the specific position where a constraint will be violated. To apply a markedness constraint to a string, the locus of violationfunctionof a markedness constraint will find the set of points where the constraint is violated. As clarified in McCarthy (2003), a localmarkedness constraint does not apply to a string; it only applies to segments. The locus function is a property of markedness constraints and its operation in a candidate (cand) is formally defined in McCarthy (2003) as follows:

The Loc function

Loc(cand) $\rightarrow\left\{\right.$ locus $\left._{1}, \operatorname{locus}_{2}, \ldots\right\}$, where locus $\mathrm{j}_{\mathrm{j}}$ is a segment in the candidate cand.

The locus function can be formalized for the constraint in (30)following McCarthy (2003) as follows:

Loc* $[\text { ai }]_{\mathrm{L}} \equiv$ Return each instance of /i/ that is immediately preceded by /a/, where /i/ is a phonological exponent of a morpheme specified as $\mathrm{L}$.

The domain of relevance for the 'locus of violation' of indexed constraints is restricted to co-indexed input-output pairs, where each constraint violation is assessed with regard to a specified location in the input. With regard to indexed markedness constraints this means that not only is the markedness constraint constrained to apply in the indexed part of the candidate, but also that the number of violations that the constraint can incur is also limited. The set of points that the locus of violation function for Loc * $[\text { ai }]_{\mathrm{L}}$ identifies for the candidate /tavara- $\mathrm{i}_{\mathrm{L}}-\mathrm{ssa} /$ is limited to the indexed morpheme,and this limitation in the locus of violation defines the locality convention of exceptional occurrences.

In Assamese, the two morphemes /-ija/ and /-uwa/ exceptionally trigger harmony in the otherwise opaque vowel /a/. This kind of triggering behavior is exceptional, as it is confined only to these two morphemes. But it is also systematic: /a/ systematically changes only when it is adjacent to the harmony triggering morpheme; i.e. if /a/ does not occur in immediate proximity of the triggering vowel, it does not harmonize (see diagram (29)). The local effect schematically represented in (29) can be captured by a locally applicable markedness constraint. The constraint which I propose to be active here is the indexed version of the contextual markedness constraint $*[-\mathrm{ATR}][+\mathrm{ATR}]_{\mathrm{L}}$.

$$
*[-\mathrm{ATR}][+\mathrm{ATR}]_{\mathrm{L}}
$$

Return each instance of [-ATR] immediately followed by [+ATR] which includes a phonological component of the morpheme lexically specified as $\mathrm{L}$.

The locality convention manifests itself in this constraint in the form of a condition on the position of violation of the constraint. This constraint is violated by the syllable which contains the [-ATR]-bearing segment only if in that position it immediately precedes a [+ATR] vowel which belongs to the morpheme specified as L. Thus, the position of violation of this constraint should be such that it is in the absolute adjacent syllabic position to the triggering morpheme specified as L. Any further instantiations of [-ATR][+ATR] are not under the jurisdiction of this constraint. The full ranking of Assamese exceptional triggering is given below in (35) and the corresponding tableau exemplifying the analysis is in(36):

$$
\begin{aligned}
& \text { Ranking: *[-ATR } \left.][+\mathrm{ATR}]_{\mathrm{L}} \gg \operatorname{IDENT}[\text { Low }] » *[-\mathrm{ATR}][+\mathrm{ATR}] \gg *[+\mathrm{ATR}-\mathrm{High}] \gg \text { IDENT[ATR }\right] \\
& \text { Indexed morphemes in the Lexicon: } /-\mathrm{ija} / \mathrm{L} /-\mathrm{uwa} / \mathrm{L}
\end{aligned}
$$

(37) /a/ harmonizes in the presence of /-ija/

\begin{tabular}{|l||c|c|c|c|c|}
\hline$/ \mathrm{mar} /+\mathrm{ija} / \mathrm{L}$ & $*[-\mathrm{ATR}][+\mathrm{ATR}]_{\mathrm{L}}$ & IDENT[Low] & $*$ [-ATR][+ATR] & $*$ [+ATR-High] & [DENT[ATR] \\
\hline \hline a. marija & $* !$ & & $*$ & & \\
\hline b. ${ }^{\circ}$ morija & & $*$ & & $*$ & $*$ \\
\hline c. morijo & & $* * !$ & & $* *$ & $* *$ \\
\hline
\end{tabular}

The lexically indexed constraint $*[-\mathrm{ATR}][+\mathrm{ATR}]_{\mathrm{L}}$ penalizes a sequence where $[\mathrm{a}]$ is followed by the triggering [i]. Note that the constraint $*[-\mathrm{ATR}][+\mathrm{ATR}]_{\mathrm{L}}$ does not refer to the entire morphemic sequence 
of /-ija/ and /-uwa/, but only to a portion of it. (37a)is ousted because it violates the highly ranked lexically indexed constraint. The choice between the two remaining candidates (37b) and (37c) is determined by the faithfulness constraint IDENT[Low] which is violated twice by the failed candidate in (37c). In the tableau below, I show how this constraint hierarchy works when there are two instances of /a/ in the input. The tableau below shows that $*[-\mathrm{ATR}][+\mathrm{ATR}]_{\mathrm{L}}$ inhibits occurrences of $[-\mathrm{ATR}][+\mathrm{ATR}]$ only in the minimal domain.

(38) Local alternation of /a/ when followed by /-ija/ or /-uwa/

\begin{tabular}{|l||c|c|c|c|c|}
\hline$/$ alax/+/uwa/L & $*[-\mathrm{ATR}][+\mathrm{ATR}]_{\mathrm{L}}$ & IDENT[Low $]$ & [-ATR][+ATR] & $*[-$ High +ATR $]$ & IDENT[ATR] \\
\hline \hline a. alaxuwa & $* !$ & & $*$ & & \\
\hline b. ${ }^{\circ}$ aloxuwa & & $*$ & $*$ & $*$ & $*$ \\
\hline c. oloxuwa & & $* * !$ & & $* *$ & $* *$ \\
\hline d. oloxuwo & & $* * * !$ & & $* * *$ & $* * *$ \\
\hline
\end{tabular}

This tableau shows the markedness requirement of the exceptional trigger /-uwa/, i.e. its local application. The indexed constraint $*[-\mathrm{ATR}][+\mathrm{ATR}]_{\mathrm{L}}$ does not apply to the initial /a/of the stem /alax/. (38a)violates the top ranked $*[-\mathrm{ATR}][+\mathrm{ATR}]_{\mathrm{L}}$. Multiple violations of the faithfulness constraint IDENT[Low] lead to the disqualification of the candidate (38c). This analysis has been presented in Mahanta (2008) and also mentioned in Pater (2009), but I now move on to discuss the exceptional typology of vowel harmony and the place of exceptional triggering in the typology.

\subsection{Revisiting locality:Towards a typology of exceptions in vowel harmony}

Locality is a fundamental insight of generative grammar. Phonological processes are known to typically operate on adjacent elements, which in turn aids the learnability of such processes. I propose that strict locality in vowel harmony in the manner argued for in the phonological literature is only to be considered an attribute of exceptional triggering. Exceptional blocking in vowel harmony does not need any additional theoretical tool of locality. In effect, both exceptional and non-exceptional blockers behave in precisely the same manner (Bakovic 2000). In both types, the blocking vowel does not allow the harmonic feature value to affect any more vowels in the direction of spreading. Exceptional triggering, on the other hand is to be understood as non-iterative harmony and it is mainly a matter of triggering an exceptional pattern on an adjacent syllable in a string. Note that the locality principle (McCarthy and Prince 1986) espoused for prosodic morphology is as follows:

A rule may fix on one specified element and examine a structurally adjacent element and no other.

McCarthy and Prince(1986) consider locality of adjacent structural elements to be a 'two elements only' configuration. Locality in these terms is seen as a process which can consider only two grammatical elements; in other words, 'grammars can only count upto two'. McCarthy and Prince (1986) argue that rules count moras $(\mu)$, syllables $(\sigma)$, or feet $(F)$ but never segments. McCarthy and Prince also reject the idea that languages count only the number of segments in a form. Templates can only count prosodic elements, and any approach which only counts segments is bound to fail. Thus McCarthy and Prince (1986) refute the templatic theory of reduplication and argue for a locality which is prosodically defined. This sort of categorical locality may also be necessary to account for exceptions in vowel harmony. As seen in (34), the locality of exceptional triggering considers only the vowel in an adjacent syllable in a string. It is important to see this distinction because exceptional triggering in vowel harmony is essentially a non-iterative process (unlike regular processes of vowel harmony) and the units of the process are confined to two adjacent syllables only.

\subsubsection{Locality and exceptional blockers}

Exceptional blockers in vowel harmony are mostly vocalic elements ${ }^{12}$ which exceptionally stem the tide of unbounded vowel harmony. Such blockers have traditionally been called opaque vowels in vowel harmony. An opaque vowel is a disharmonic vowel, and the reason for the disharmonicity of the opaque vowel can be either phonological or morphological. Morphologically governed exceptional blockers or opaque vocalic segments do not behave any differently from opaque segments which are

\footnotetext{
${ }^{12}$ Although in the literature on vowel harmony, it is not uncommon to find consonants which also block vowel harmony (see Archangeli and Pulleyblank 1994; Krämer 2003; Mahanta 2008;Woock and Noonan 1979).
} 
phonologically governed. To analyze the striking similarity of opaque vowels which are both phonologically driven as well as morphologically governed, we consult Bakovic (2000) where this is explicitly discussed in the context of Turkish vowel harmony.

Turkish vowel harmony is such that all vowels in a word must bear the same feature values for [Back] and [Round]. [-High] vowels systematically fail to harmonize with the [Round] value of root vowels and are therefore opaque to [Round] harmony. Unlike these cases of phonological opacity, the vowel of the Turkish progressive suffix is always [+Back +Round] and is hence opaque to both [Back] and [Round] harmony. The Turkish progressive suffix([-jor]) is exceptionally opaque and can be analysed with the aid of a lexically indexed faithfulness constraint ranked above the agreement constraint. This is shown for the Turkish progressivein (40)below.

(40) Minimal violation in morphological opacity

\begin{tabular}{|c|c|c|c|}
\hline $\begin{array}{l}\text { iste-jor-im 'want } \\
\text { (FIRST PERSON PROGRESSIVESINGULAR.)' }\end{array}$ & IDENT[Round $]_{\text {PROG }}$ & AGREE[Round] & IDENT[Round] \\
\hline a. isti-jar-im & $* !$ & & * \\
\hline b. isti-jor-um & & $*$ & $*$ \\
\hline c. isti-jor-im & & $* * !$ & \\
\hline
\end{tabular}

The candidate in (40a) is unfaithful to the underlying [Round] value of the progressive morpheme vowel, resulting in violation of the indexed faithfulness constraint. Candidate (40b) is the optimal one as it is faithful to the underlying [+Round] value of the progressive morpheme vowel, even though it violates agreement demanded by AGREE[Round].

Bakovic also reliably demonstrates that in the presence of both phonologically predictable opaque vowels and morphologically induced exceptionally opaque vowels, an affix vowel uniformly agrees with the opaque vowel if it is adjacent to it. This shows that in vowel harmony, blocking by vowels needs no extra requirement of locality. Locality in phonological blocking is ubiquitous in vowel harmony systems (as also in Assamese; see Section 1.3 and the examples and tableaus therein) and therefore blocking is essentially the same in both exceptional and regular vowel harmony.

\subsubsection{Non-existence of transparent vowels in exceptional patterns}

The purpose of the previous section was to demonstrate, with the aid of opaque vowels which are either phonologically determined or morphologically constrained, that exceptional blocking shows the same requirements of locality under both conditions (contra Finley 2010). Given this behavior and its locality in exceptional triggering situations, a locality convention in the analysis of exceptions must restrict the absence of morphologically idiosyncratic transparent vowels in vowel harmony languages. So-called transparent vowels cannot bear one of the two values of the harmonic feature, but these are different from opaque vowels in that they seem to permit the incompatible value to pass through them, allowing agreement between the vowels on either side, while the transparent vowel is itself incompatible with the feature values of the vowels on both sides.

The obvious explanation for the absence of morphologically idiosyncratic transparent vowels is that vowel transparency establishes a non-local relation, and therefore transparent vowels are not a choice which can be exploited by exceptional morphemes. Therefore, the typology of exceptional occurrences in vowel harmony excludes vowel transparency by incorporating a strict locality criterion between trigger and target in exceptions in vowel harmony. A constraint which typically operates to execute locality in exceptional vowel harmony is the following:

Locality in exceptional vowel harmony:

Only adjacent elements in a string (defined as syllable, mora, foot) can bear the phonological exponence of morphological elements.

This locality criterion excludes the presence of transparent vowels in exceptional patterns of vowel harmony, but it includes exceptional triggering.

\subsection{A typological sketch of exceptions in vowel harmony}

The typology of exceptions in vowel harmony needs to be stringently based on the locality criterion. While exceptional triggers will always trigger non-iterative harmony, exceptional blockers will not allow the harmonic feature value to percolate. In this context the typology of exceptions in vowel harmony presented by Finley (2010) becomes relevant. Finley's typology considers all exceptional patterns in vowel harmony languages to be morpheme-bound. I propose that there needs to be a more fine-grained distinction between the different types of exceptionalities regarding their respective locality conditions. Finley's typology divides the exceptional patterns in vowel harmony into 
exceptional undergoers, exceptional non-undergoers, and exceptional triggers. Finley seeks to isolate exceptional triggers from exceptional non-triggers and exceptional undergoers from exceptional nonundergoers. The exceptionally undergoing vowel harmony morpheme in Korean (which is otherwise not a vowel harmony language) allows for non-iterative vowel harmony. Exceptional vowel harmony in Korean is observed only in the verbal morpheme, where the verbal morpheme alternates with [a] if the vowel to its left is [a] or [o]. In the presence of other vowels, the same vowel surfaces as [ə].

(42) The Morpheme-Bound Nature of Vowel Harmony in Korean(Cho 1994; Kim 2000; Lee 1998; data adapted from Finley 2010):

a. [mog-dai-an-a-t'a] 'eat' (NEGATIVE PAST)

b. [məg-o-t'a] 'eat'(PAST)

When the negative marker [an] intervenes between the stem [məg] and the verbal morpheme, the verbal morpheme alternates with [a]. In (42b), the past tense morpheme's vowel is [a], even though the verbal morpheme [ə] immediately precedes this vowel: [məg-ə-t'a] vs. [məg-dai-an-a-t'a]. The example above shows that whenever a harmonic relation is established exceptionally, the result is always non-iterative.

While Finley's typology can separate the behavior of exceptional non-undergoers from exceptional undergoers, this typology fails to predict and account for the non-existence of exceptionally transparent vowels which are also exceptional non-undergoers. Exceptionally transparent vowels are not only absent crosslinguistically, but they are also predicted to be non-existent by the very nature of locality of exceptions. Exceptionally transparent vowels which would establish a non-local relation between the trigger and target are categorically prevented from being available as one of the choices of exceptionality in vowel harmony languages. On the other hand, exceptional non-triggers, although predicted by Finley to be non-existent, are predicted by the theory of exceptionality in vowel harmony, and a high-ranked indexed markedness constraint would be able to account for it, if such a pattern is attested.

This excursus on the typology of exceptions in vowel harmony shows us that there may be only two types of exceptionality in vowel harmony, and while one type is subject to a criterion of locality, the other does not need any additional requirements.

(i) Exceptional harmony. This is demonstrated by the non-iterative harmony in exceptions in Assamese vowel harmony and Korean harmony. Assamese exceptional triggering and Korean exceptional undergoers are both instances of exceptional harmony.

(ii) Exceptional blocking. This is demonstrated by exceptional morphological blocking in Turkish. Insofar as locality is concerned, this type of morphological blocking is not distinct from phonological opacity.

The two unattested patterns are exceptional non-triggers of harmony and exceptionally transparent vowels. On one hand, if exceptional non-triggers are found to exist, then exceptional non-triggers can be predicted to fall under the locality pattern exhibited by exceptional blocking (i.e. bound to the exceptional morpheme). On the other hand, if exceptionally transparent vowels are found to be prevalent in vowel harmony languages, then this will contravene the locality principle which has been espoused for exceptional occurrences.

\section{Alternative approaches to exceptional phenomena within optimality theory}

In recent theoretical discussion in the OT framework, there has been considerable interest in the way exceptional morphological interferences in phonology can be modeled (Anttila 2002; Inkelas and Zoll 2003; Pater 2000, 2009). It is of special interest in an OT framework where all constraints are universal and individual grammars are a result of permutations of these constraints. In the cophonology approach of Antilla (2002), morphemes select their own ranking from a set of partially ordered constraints. Accordingly, only constraints that are unranked in the grammar can have lexically specified rankings. I will not go into the details of the cophonology approach. (See Anttila 1997, 2000, 2002; Inkelas 1998; Inkelas and Zoll 2005; Orgun 1996, 1998, 1999; Orgun and Inkelas 2002 for an elaboration of the framework; and Pater 2000, 2006, 2009, for arguments against indexed constraint rankings and in favor of constraint indexation.) Among the diacritic approaches, the ones favoring faithfulness-only constraint indexation are many and varied (e.g. Fukuzawa 1999; Itô and Mester 1999, 2001; KraskaSzlenk 1997, 1999; see also Alderete 2001; Benua 2000). It has been argued that morpho-phonological processes are the result of the grammar at large. The indexation of faithfulness constraints only was supposed to lend force to the argument that such grammar dependent processes have manifest limits on 
their range of occurrences (e.g. Alderete 2001; Benua 1997; Itô and Mester 1999). It was argued that lexical indexation can pose limitations on the scope and extent of exceptional occurrences simply because of the prohibition against the indexation of markedness constraints. Therefore, 'faithfulness only' indexation predicts languages in which there would be a limitation on the extent of variation possible in the markedness patterns of exceptional processes. The local conjunction approach adopted by Lubowicz showed that derived environment blocking effects can only be captured by the conjunction of markedness and faithfulness constraints. In the following subsections, I show how each of these approaches would lead to wrong results while analyzing exceptional vowel harmony in Assamese.

\subsection{Morpheme-specific exceptions in cophonology theory}

A theoretical approach which would founder with respect to the Assamese patterns of morphophonological interaction is that of cophonology, more specifically in the manner argued by Anttila (2002; one of the main proponents of the cophonology approach). In general, cophonology requires exceptionalities in the lexicon and morphology to be analyzed with the aid of lexically specified rankings of constraints which are already present in the grammar. In the approach propagated by Anttila (2002) only pairs of constraints whose ranking is unspecified in the general case can have lexically specified rankings. When a lexical item is unspecified for the respective ranking, then it should show variation.

I have shown in Section 2.1 that lexical indexation accounts for non-iterative raising in the context of a pair of morphemes in Assamese. The indexed markedness constraint bans a configuration of two adjacent vowels, of which the first one is [-ATR] and the second is [+ATR]. Since the indexed constraint is only sensitive to [ATR] alteration, it checks whether there is an adjacent [-ATR] vowel, which is repaired even if the [+ATR] feature of the vowel is contributed by another morpheme. While this is feasible in a lexical indexation approach, a cophonology analysis would predict iterative application of raising in stems with more low vowels than just the final one in the presence of the affixes in question. The remainder of this section shows how the approach advocated by cophonology will not work for the Assamese data. According to the lexically indexed constraint ranking approach, only unranked constraints can be lexically specified. In Assamese, the relevant unranked constraints would be IDENT[Low] and *[-ATR][+ATR]. The specific lexical items in the lexicon then choose their ranking from the unranked pair. Accordingly, indexation of constraint ranking will produce [kopahi] 'made of cotton' and [morija] 'beat' respectively in each of the two lexical items listed in (44a) and (44b).

General constraint ranking in the language:

*[+ATR +Low $]$ » IDENT[Low $], *[-\mathrm{ATR}][+\mathrm{ATR}]$

(44) Constraint ranking in the lexicon:

a. kopah-i $\mathrm{i}_{\text {IDENT[Low] }) ~[-A T R][+A T R]}$

b. $\quad$ mar-ija $_{*[-\mathrm{ATR}][+\mathrm{ATR}] » \operatorname{IDENT}[\text { Low }]}$

It is quite easy to show that the indexed constraint ranking approach would then generate *[oloxuwa] for the input /alax-uwa/ as a result of indexed constraint ranking. The tableau below shows how cophonology theory would predict incorrect results for the input /alax-uwa/.

(45) $\quad$ alax $-\mathrm{uwa}_{*[-\mathrm{ATR}][+\mathrm{ATR}] » \operatorname{IDENT}[\mathrm{Low}]}$

\begin{tabular}{|l||c|c|c|}
\hline /alax/+/uwa/ & $*[-\mathrm{ATR}][+\mathrm{ATR}]$ & IDENT[Low] & IDENT[ATR] \\
\hline \hline a. alaxuwa & $* !$ & & \\
\hline b. $:$ aloxuwa & $* !$ & $*$ & $*$ \\
\hline c. *oloxuwa & & $* *$ & $* *$ \\
\hline
\end{tabular}

The candidate in $(45 \mathrm{c})$ would be the predicted outcome in ranking indexation. The actual output in (45b) incurs a fatal violation of the constraint * [-ATR][+ATR].

Anttila (2002) also presents this model to establish a connection between exceptionality and variation, so that whenever the constraints are unranked, the resultant output has the potential to vary either on the markedness or on the faithfulness dimension. This kind of variation is not attested in Assamese, and therefore this attribute of cophonology theory cannot be applicable to all instances of exceptionality in the grammar of languages. Further, as argued in Pater (2006, 2009), Anttila (2002) 
cannot elegantly capture local effects of constraints which are active in exceptional triggering and blocking.

I now move on to emergent [Back] harmony in Assamese, where a completely innovative [Back] harmony is triggered by the raising of / $\mathrm{a} /$ if there are preceding mid vowels.

\section{4 /a/-raising and [Back] alternation: Data and problems}

In this section I lay emphasis on some of the intricacies of vowel harmony phenomena in the presence of mid vowels, which have not been elaborated upon until now. Section 2.1 dealt with the low vowel /a/ which exceptionally undergoes harmony when followed by /-ija/ and /-uwa/. Further complications arise when /a/ occupies the second position from the left in the root but there is a [-ATR] mid vowel in the initial position.

In sequences like $/ \mathrm{C} \varepsilon \mathrm{CaC} /+/ \mathrm{ija} /$, where the ouput is [CeCeCija], the derivation presents itself as a case of what is called emergent [Back] harmony in Assamese in this paper. Assamese vowel harmony is iterative and regressive, hence if /a/ undergoes harmony and produces a [+ATR] output, it is plausible that the resultant $[+\mathrm{ATR}]$ vowel will also trigger harmony in the preceding $/ \varepsilon /$ and $/ \mathrm{\rho} /$. Hence in instances of $/ \mathrm{C \varepsilon CaC} /+/ \mathrm{ija} /$, it could be predicted that the outcome of /a/-raising would result in [CeCoCija] because $[\mathrm{CeCoCija}]$ will violate the constraint driving iterative vowel harmony, i.e. * $[-$ ATR][+ATR]. A quick look at the data below shows that this prediction is true, but the attested pattern of /a/-raising in this environment shows another alternation along with /a/-raising. In disyllabic stems, where /a/ is preceded by a mid vowel, apart from [+ATR] harmony, the feature that /a/ assumes for harmony is determined by the root-initial vowel. In other words, the presence of an initial mid front vowel leads to the emergence of front harmony in all these cases, where $/ \mathrm{C} \varepsilon \mathrm{CaC} /+/ \mathrm{ija} / \rightarrow[\mathrm{CeCeCija}]$.

$$
\text { /a/-raising triggered by /-uwa/ }
$$

$\begin{array}{llllll} & \text { Word } & \text { Gloss } & \text { Suffix } & \text { Derivation } & \text { Gloss } \\ \text { a. } & \text { clah } & \text { 'laziness' } & \text { uwa } & \text { elehuwa } & \text { 'lazy' } \\ \text { b. bozar } & \text { 'marketplace' } & \text { uwa } & \text { bozoruwa } & \text { 'cheap' } \\ \text { c. polax } & \text { 'fertiliser' } & \text { uwa } & \text { poloxuwa } & \text { 'fertile' } \\ \text { d. kesa } & \text { 'raw' } & \text { uwa } & \text { keseluwa } & \text { 'rawness' } \\ \text { e. deka } & \text { 'youth'(male) } & \text { uwa } & \text { dekeruwa } & \text { 'youthfulness' }\end{array}$
/a/-raising triggered by /-ija/

$\begin{array}{llllll} & \text { Word } & \text { Gloss } & \text { Suffix } & \text { Derivation } & \text { Gloss } \\ \text { a. kopal } & \text { 'destiny' } & \text { ija } & \text { kopolija } & \text { 'destined' } \\ \text { b. } & \mathrm{d}^{\mathrm{h}} \text { Emali } & \text { 'play' } & \text { ija } & \mathrm{d}^{\mathrm{h}} \text { emelija } & \text { 'playful' } \\ \text { c. } & \text { golap } & \text { 'rose' } & \text { ija } & \text { gulopija } & \text { 'pink' }\end{array}$

The pattern observed above shows that when /-ija/ and /-uwa/trigger harmony, /a/ changes to either [e] or [o], depending on the [Back] value of the root-initial vowel. The process of /a/-raising is sensitive to morphological factors, but [Back] harmony is sensitive to /a/-raising. In other words, only an underlying /a/ which undergoes raising may alter its [+Back] value. This emergent [Back] harmony shows the characteristics of a derived environment process.

The process addressed here requires the presence of / $\mathrm{a} /$, which is a candidate for raising because of the presence of the specific morphemes. There is a morphological domain restriction on this phonological process, as it is blocked if the preceding / $\varepsilon-/$ or /o-/ is a prefix vowel. The allegiance to the morphological boundary of a prefix so that the prefixal vowel remains unchanged in its [Back] specification is shown by the examples below: 


$\begin{array}{llllllll} & \text { Prefix } & \text { Gloss } & \text { Root } & \text { Gloss } & \text { Suffix } & \text { Derivation } & \text { Gloss } \\ \text { a. } & \varepsilon & \text { 'one' } & \text { sal } & \text { 'roof' } & \text { ija } & \text { esolija } & \text { 'one roof-ed' } \\ \text { b. } & \varepsilon & \text { 'one' } & \text { dal } & \text { 'branch' } & \text { ija } & \text { edolija } & \text { 'one branch-ed' } \\ \text { c. } & \varepsilon & \text { 'one' } & \text { pat } & \text { 'leaf' } & \text { uwa } & \text { epotuwa } & \text { 'one leaf-ed' } \\ \text { d. } & \text { so } & \text { 'six' } & \text { mah } & \text { 'month' } & \text { ija } & \text { somohija } & \text { 'six months old' }\end{array}$

In the examples in (48) the root $/ \mathrm{a} /$ does not change its intrinsic [+Back] feature value to that of the preceding prefixal vowel. The reason for this behavior is dependent on the affiliation of / $/ \varepsilon /$ and $/ \mathrm{o}-/$ as prefixal vowels. Under such circumstances, the [Back] value that the vowel /a/ alternates with depends on the intrinsic [+Back] value of /a/, so that it invariably changes to [o] instead of [e]. Further, /a/ is morphologically sensitive to [ATR] harmony but it is not part of the regular phonological spreading process.

To summarize, there are two phenomena involving preceding vowels: Prefix and root mid and high [-ATR] vowels harmonize when they precede [+ATR] vowels, but preceding root mid [ATR] vowels trigger backness harmony in harmonizing / $/$ / but prefix vowels do not. In order to make this clearer, I schematize this below:

Regressive [ATR] harmony and progressive [back] harmony Regressive [ATR] harmony

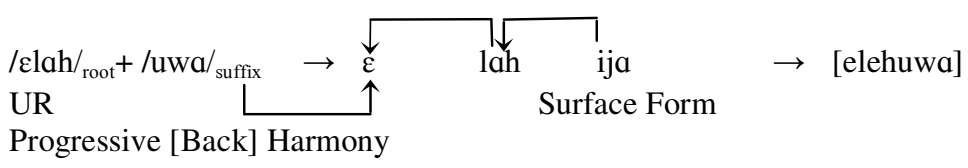

(50) No progressive [Back] harmony if the preceding mid vowel is prefixal Regressive [ATR] harmony

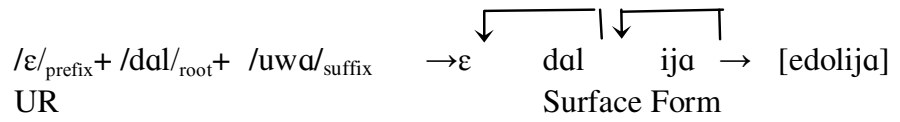

As shown above, prefixal vowels fail to initiate progressive front harmony. If exceptional /a/-raising is demonstrated in the presence of preceding mid root vowels, the root vowel determines the [Back] feature that /a/might assume, so that it becomes [+ATR] ([e] or [o]). It is clear from this behavior that the root-initial vowel is responsible for initiating a type of progressive [ \pm Back] harmony, where the vowel which raises to satisfy [ATR] harmony can also change its [Back] specification in order to agree with the preceding vowel's specification for [Back]. These changes fail to apply if the preceding mid vowel belongs to the prefix.

Before proceeding to an analysis, it may be useful to summarize the facts involved in harmony in Assamese. /a/ undergoes regressive [+ATR] harmony and occasionally progressive [Back] harmony, and both of these occurrences happen in the presence of /-ija/ and /-uwa/ (although progressive [Back] harmony is not directly dependent on /-ija/ and /-uwa/, but rather on a raised /a/). The locality conditions are such that /a/ becomes [+ATR] only if the following vowel is a part of [-ija] or [-uwa]./a/ agrees in backness with a preceding mid root (but not prefix or high/low) vowel, if one exists; otherwise /a/ maps to [o]. Iterativity in this exceptional domain appears when an underlying non-/a/ [ATR] root or prefix vowel preceding a harmonized /a/ also becomes [+ATR], but if /a/ is the preceding vowel, it never harmonizes.

\section{1/a/-raising and [Back] alteration: The relative importance of faithfulness to [Back] values}

One of the requirements for emergent harmony is that the root-initial vowel be a mid vowel. This process results in simultaneous change of the [Back] quality of /a/ along with its raising, i.e. it is not only the [-ATR] quality of the mid vowel which changes, but also the [Back] and [-ATR] qualities of the vowel /a/.Whenever the root-initial vowel is not a mid-vowel, the process of harmony is blocked. Some examples are in (51), e.g. /misa/+ [1] +/ija/ maps to the output [misolija] 'liar' and not 
*[miselija], which would result in an output where the root initial high front vowel does not trigger [Back] harmony. The analysis for [misolija] is straightforward when IDENT[Back] is included in the hierarchy of constraints as below:

(51) IDENT[BACK] suffices for the analysis of input /misa/+[1]+/ija/

\begin{tabular}{|l||c|c|c|c|}
\hline$/$ misa/+[1]+/ija/ & $*[-\mathrm{ATR}][+\mathrm{ATR}]_{\mathrm{L}}$ & IDENT[Back] & IDENT[Low $]$ & $*[-\mathrm{ATR}][+\mathrm{ATR}]$ \\
\hline \hline a. misalija & $* !$ & & & $*$ \\
\hline b. miselija & & $* !$ & $*$ & \\
\hline c. ${ }^{\circ}$ misolija & & & $*$ & \\
\hline
\end{tabular}

The tableau above shows how the constraint on faithfulness to [Back] values alongwith the indexed constraint $*[-\mathrm{ATR}][+\mathrm{ATR}]_{\mathrm{L}}$ is able to provide the correct output in the evaluation of /misolija/ 'liar'. The incorporation of IDENT[Back] also does not jeopardize our analysis of exceptional phenomena examined up to now. When there are no preceding mid vowels, /a/ assumes its own inherent [+Back] quality in the process of raising. Therefore, IDENT[Back] remains unviolated in such circumstances. The bisyllabic root/alax/+/uwa/ can be analyzed to show how IDENT[Back] is integral to the analysis:

(52) Incorporation of IDENT[Back] to the analysis of input/alax/+/uwa/

\begin{tabular}{|l||c|c|c|c|}
\hline /alax/+/uwa/ & $*[-\mathrm{ATR}][+\mathrm{ATR}]$ & IDENT[Back & IDENT[Low] & $*[-\mathrm{ATR}][+\mathrm{ATR}]$ \\
\hline \hline a. alaxuwa & $* !$ & & & $*$ \\
\hline b. alexuwa & & $* !$ & $*$ & $*$ \\
\hline c. ${ }^{\circledR}$ aloxuwa & & & $*$ & $*$ \\
\hline
\end{tabular}

The tableau above shows that IDENT[Back] blocks candidate (52b), which is harmonically bound to the optimal candidate in (52c).(52b)does not violate the highest ranked indexed constraint * $[-$ ATR $][+A T R]_{L}$ and it satisfies the lower ranked IDENT[Low] just like the optimal candidate, so IDENT[Back] is absolutely necessary to prevent the crashing of this derivation.

All other environments which could be potential sites for [Back] harmony also do not instantiate this type of harmony. [Back] harmony is not an option if there is a word where [-ija] or [-uwa] triggers [ATR] harmony, but where the root-initial mid vowel is followed by a [+High -ATR] vowel. In such an environment, the root-initial mid vowel does not trigger front harmony, as illustrated by the examples below:

(53) Root-initial midvowel does not lead to [Back] harmony if there is no medial /a/

$\begin{array}{lllll} & \text { Word } & \text { Gloss } & \text { Word } & \text { Gloss } \\ \text { a. } & \text { dek } k^{\mathrm{h}} u t a & \text { 'one who sees' } & \operatorname{dek}^{\mathrm{h}} \mathrm{uwa} & \text { 'one who shows } \\ \text { b. } & \text { kerun } & \text { 'disease (of tree/plant)' } & \text { kerunija } & \text { 'infested with worms' }\end{array}$

In the examples above, if the input is /CعCuC-ija/, the resulting output is [CeCuCija], and * $[\mathrm{CeCiCija}]$, the unattested candidate, does not show up as victorious because an underlying medial / $/$ is not required in order to result in a derivation showing agreement in [Back] values.

Although IDENT[Back] is indispensable, the use of faithfulness constraints alone does not lead us to a satisfactory analysis of the back harmony phenomenon. The back harmony problem needs to be addressed as a reflex of a prohibition already present in the phonology of Assamese - that is, the avoidance of sequences of front and back vowels in the root. Neither the addition of IDENT[Back] nor any other faithfulness constraint ${ }^{13}$ alone will predict the attested outputs with [Back] harmony, where

\footnotetext{
${ }^{13} \mathrm{~A}$ reviewer suggests the option of positing a special faithfulness constraint IDENT[Back]/[-Low] which specifies that back values of input [-Low] vowels should be preserved. Faithfulness constraints of any type, special or general, are not able to enforce front harmony in the data attested here. The constraint IDENT[Back]/[-Low] would be ineffective in prohibiting the candidate without any [Back] harmony from emerging as the successful candidate, such that when the input is /عlah/+/uwa/, both the unsuccessful candidate */elohuwa/ and the actually attested form /elehuwa/ will fare equally well with the constraint IDENT[Back]/[-Low]. In the absence of any other markedness constraint which prohibits the /a/ $\rightarrow$ [o] alternation, the evaluation will then select */elohuwa/ because it will perform better with IDENT[Back].
} 
the initial front vowel leads to the alternation of the $/ \mathrm{a} /$ in the following syllable as in /elah/+/uwa/ $\rightarrow$ [elehuwa] 'lazy'. In evaluating inputs like /عlah/+/uwa/, the constraint hierarchy above will predict *[elohuwa] instead of [elehuwa]. This is because IDENT[Back] does not permit changes in the [Back] values of the input, and will therefore select *[elohuwa] as opposed to the attested output [elehuwa] which will violate it.

(54) Failure to predict /elehuwa/ after the addition of IDENT[Back]

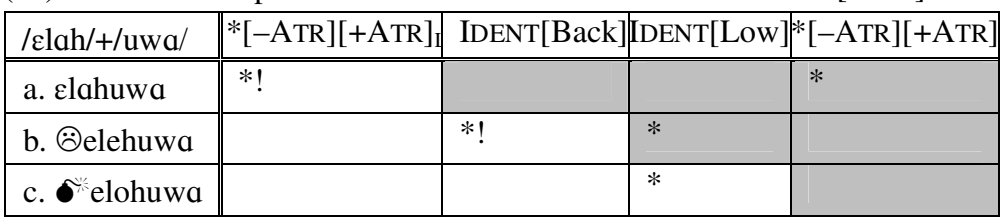

The reason for the resistance of $/ \mathrm{a} /$ to an account based on general markedness and faithfulness constraints is that it would be a far cry from presenting an analysis of the resultant harmony that the derived /a/undergoes under the influence of the preceding mid front vowel / $/$ /. In the section below we address the problem of a non-underlying / $\mathrm{a} /$ undergoing front harmony and try to contextualize it to the phonological lexicon of the language.

\subsection{Derived environment effect in harmonic patterns: The analysis}

Cases where phonological rules are only applicable to derived structures but are systematically blocked in nonderived environments are known to be instances of non-derived environment blocking (NDEB; Kiparsky 1993). A derived structure is one where (a) the segments participating in the phonological process traverse a morpheme boundary, or (b) the relevant segment, i.e. the segment undergoing a phonological process, arises as a result of another phonological process (applying in the same cycle, as per Kiparsky 1982 and Mohanan 1986). In much of the literature which has dealt with non-derived environment blocking, these two processes have been identified as morphological NDEB and phonological NDEB, respectively.

I argue below that the derived environment effect (DEE) in Assamese is not necessarily blocked in non-derived domains. Regular phonological processes are often blocked from applying in languages if the result would lead to some phonologically ill-formed structure. The Assamese derived environment effect shows that there is no active blocking in non-derived environments and this is evident from factors related to the occurrence of the trigger and target in phonologically simplex domains. As will be shown shortly, there is a paucity of data showing the relevant trigger and target occurring in that environment. Apart from the absence of non-derived [e...o] sequences, even in derived domains the phonological DEE is the result of a derived environment created by the presence of an exceptional morpheme. This, however, does not make it a morphological DEE as this phonological DEE is also not productive in morphologically complex domains. Wherever the boundary of the trigger and target span a morpheme boundary, the DEE is not seen.

A scanning of the most comprehensive Assamese dictionary ${ }^{14}$ showed that apart from restrictions on sequences of [-ATR] and [+ATR] demonstrating [ATR] vowel harmony (see Section 1), constraints on sequential occurrences are extended to mid vowel sequences also, but only in a specific domain. Dictionary entries showed that in roots, the sequence / $\varepsilon$... / is definitely marked, even though it is not non-existent. Mahanta (2008) found only four lexical items with underlying / $\varepsilon$.../ sequences, three of which were loanwords. They are given below:

\section{(55) Sequences of $/ \varepsilon /$ followed by $/ \mathrm{\jmath} /$}

$\begin{array}{lll}\text { a-initial } & \text { Gloss } \\ \text { a. } & \text { tero } & \text { 'thirteen' } \\ \text { b. beson } & \text { 'powdered pulse' } \\ \text { c. reson } & \text { 'provisions' } \\ \text { d. beton } & \text { 'salary' }\end{array}$

\footnotetext{
${ }^{14}$ The dictionary scanned for this purpose was Barua (1900/2007).
} 
While there was no discussion of the productivity of these sequences, a more thorough investigation has revealed that these are among the very few words containing underlying lexical / $\varepsilon . . . /$ sequences. Interestingly, we may be tempted to surmise that these sequences of mid [-ATR] vowels do not undergo raising, either because of the opacity of the final /n/ or because in a word like /tero/ suffixation is not possible. There is no way to test if these words would have resulted in harmony because /beson/, /reson/, and /beton/ are also loan words and non-native loans normally do not combine with native suffixes. ${ }^{15}$ Therefore, even though it is the case thattheselexical items do not lead to the derivation of [e...o] sequences as a result of [ATR] harmony, either because these sequences are blocked by the word-final nasal or because of the absence of morphological additions, what is to be noted is that / $\varepsilon \ldots$. / sequences and their corresponding [+ATR] values, i.e. [e...o] sequences, are severely restricted throughout the phonology. The result of such combinatorial restrictions is that while a few instances of [-ATR] front and back mid vowels are present in the phonological lexicon, there is avoidance of sequences of [+ATR] front and mid back vowels. This shows that there is tacit avoidance of words with sequences of [e...o] in the root, by restriction of underlying occurrences of [-ATR] mid vowel of $/ \varepsilon \ldots . /$ sequences, which would become illicit [e...o] sequences whenever [ATR] harmony applied. While no constraints were needed to account for this seemingly accidental absence of abundance of sequences of [e...o], a deeper investigation has shown that the avoidance of front and back mid vowels in a phonologically derived domain is the result of such a prohibition's presence in the core phonology. The following examples show that $/ \varepsilon /$ followed by $/ \mathrm{a} /$ sequences are the result of suffixation of $/ \mathrm{s} /$ to bases containing $/ \varepsilon /$.

\begin{tabular}{lll} 
(56) & \multicolumn{2}{c}{ Suffixation of $/ \mathrm{s} /$ to bases containing / $\varepsilon /$} \\
& $\varepsilon$-initial & Gloss \\
a. & er & 'leave' (SECOND PERSON FAMILIAR) \\
b. & $\mathrm{k}^{\mathrm{h}}$ elo & 'play' (SECOND PERSON FAMILIAR) \\
c. & sepo & 'squeeze' (SECOND PERSON FAMILIAR) \\
d. & xeko & 'heat' (SECOND PERSON FAMILIAR)
\end{tabular}

We can now conclude that the accidental gap of the absence of [e...o] in roots in the phonology of Assamese is not so accidental, and the reason for this gap may be assigned to a constraint prohibiting unbridled occurrences of front and back mid vowels. Alternatively, one can analyze the absence of these instances with a constraint allowing front harmony, such as AGREE[BACK]. While that may be plausible, it must be borne in mind that there are no instances of front harmony holding in all domains, not across a morphological boundary. More importantly, front harmony is not found among the [-ATR] counterparts of [e] and [o]. High vowels never demonstrate an inclination for front harmony, and the process must be limited only to mid vowels. In such cases, cross-linguistic evidence for the occurrence of such a pattern of front/back harmony among mid vowels (restricted to root vowels only) will be quite marked.

The other reason for the absence of [e...o] sequences may be the universal markedness of mid back rounded vowels. Studies presenting the markedness of [o] over [e] are available from work independent of the data attested in Assamese. Crothers (1978), in his hierarchy of implicational universals, has shown that languages with six, seven, or eight vowel inventories generally prefer to have [e] in their vowel inventories. [o] figures lower in this implicational hierarchy, which means that only those languages which have more than eight vowels will normally prefer to have [o]. [e] is also more preferred than [o] whenever there is vocalic epenthesis. (Some examples are Spanish(Harris 1986ab, 1991, 1999), Farsi (Shademan 2003), and Mohawk(Postal 1968).) The relative paucity of languages which use[o] as an epenthetic vowel is also a pointer in the direction of the markedness of [o] vis-a-vis $[\mathrm{e}] .^{16}$

The Assamese data do not provide evidence for iterative front harmony across morpheme boundaries. We find many examples in which such highly marked segments are permitted only in prominent positions, where prominent includes stressed, word-initial, and root segments (see Beckman 1995, 1997, 1998; Steriade 1995; Zoll 1996, 1997). Therefore, the constraint which is required to

\footnotetext{
${ }^{15}$ Another word /xehotiya/ (also cited in Mahanta 2008) shows that [e...o] does not occur in the root because [o] is a part of the suffix: /xeh/+/otiya/. These restrictions in the non-derived domain do not extend to morphologically complex words and shows that such combinations of $/ \varepsilon \ldots o /$ are highly productive.

${ }^{16}$ The markedness of rounded back vowels has been captured by Kaun (1995) by using the constraint *ROLO, a featural markedness constraint which prohibits vowels which are pronounced with a lower jaw position.
} 
analyze this part of the Assamese data is a markedness constraint which prohibits occurrences of the vowel [o]. In order to account for this we posit a licensing constraint prohibiting instances of the mid back vowel in non-licensed positions.

LICENSE[-High -Low +Back] (abbreviated to LICENSE[o] below):

[-High-Low + Back] is licensed in the root and/or in the root-inital position.

LICENSE[-High -Low +Back] has the effect that a mid back vowel must be in the root, and it must be associated with a following [+High +ATR] vowel, as in /bohi/, 'book' /batori/, 'news' /porohi/ 'day before yesterday' or /xogun/ 'vulture'.

Prominent positions such as roots and initial syllables are also often dependent on higher-ranking faithfulness constraints, as has been well documented; see for example McCarthy and Prince (1995) and Beckman (1995, 1997, 1998). Therefore, I also include another constraint, ROOT-INITIAL IDENT[Back], in order to allow backnesss assimilation only if the vowel belongs to the root.

\section{ROOT-INITIAL IDENT[Back]}

Assign a violation mark if the root initial vowel changes its value for [Back].

ROOT-INITIAL IDENT[Back] protects the alteration of underlying [Back] vowels. Thus the markedness constraint in (57)conflicts with the constraint in (58), which has the function of preventing / $\varepsilon /$ from alternating with the back vowel [o]. The former constraint penalizes an input $/ \supset /$ that surfaces as [o] and the latter militates against the change from $/ \varepsilon /$ to [o]. In the analysis that follows I account for the phonological blocking effects described above. The first constraint required is the specific faithfulness constraint in (58)which militates against a change of back values. The second component is the markedness constraint in (57) which prohibits a sequence of two adjacent front and back mid vowels. The combined effect of these constraints is shown below:

(59) $[$ Back] harmony if the input is $/(\mathrm{C}) \varepsilon \mathrm{CaC} /+\mathrm{uwa} /$

\begin{tabular}{|c|c|c|c|c|c|}
\hline /Elah/+/uwa/ & $\begin{array}{l}\text { ROOT-INITIAL } \\
\text { IDENT[Back] }\end{array}$ & LICENSE[o] & IDENT[Back] & IDENT[Low] & $*[-\mathrm{ATR}][+\mathrm{ATR}]$ \\
\hline a. elehuwa & & & $*$ & * & \\
\hline b. olohuwa & $* !$ & & * & * & \\
\hline c. elohuwa & & $* !$ & & * & \\
\hline
\end{tabular}

The constraint RoOT-INITIAL IDENT[Back] does not allow for the changing of root-initial [Back] values.

The following tableau shows the evaluation of theinput $/ \mathrm{CaCaC} /+/ \mathrm{uwa} /$ and how the new markedness constraint and the positional faithfulness constraints generate the attested outputs.

(60) [Back] harmony if the input is /(C)aCaC/+/uwa/

\begin{tabular}{|l||c:c|c|c|c|c|}
\hline /alax/+/uwa/ & $\begin{array}{c}\text { ROOT-INITIAL } \\
\text { IDENT[Back] }\end{array}$ & $\begin{array}{c}*[-\mathrm{ATR}] \\
{[+\mathrm{ATR}]_{\mathrm{L}}}\end{array}$ & $\begin{array}{c}\text { LICENSE } \\
{[\mathrm{o}]}\end{array}$ & IDENT[Back] & $\begin{array}{c}\text { IDENT } \\
{[\text { Low }]}\end{array}$ & $\begin{array}{c}*[-\mathrm{ATR}] \\
{[+\mathrm{ATR}]}\end{array}$ \\
\hline \hline a. alaxuwa & & $* !$ & & & & $*$ \\
\hline b. alexuwa & $* !$ & & & $*$ & $*$ & $*$ \\
\hline c. ${ }^{\circ}$ aloxuwa & & & $*$ & & $*$ & $*$ \\
\hline
\end{tabular}

A markedness constraint which has been dormant until now becomes active in such a way that GENERAL FAITH» $M$ » ROOT FAITH.This ranking gives us the emergent pattern under analysis in this paper. The blocking of [o] leads to an emergent harmony pattern, which can be accounted for by the ranking RoOTFAITH» $\mathrm{M} »$ FAITH in the OT model.

\subsection{The Emergence of the unmarked analysis vis-à-vis other contending analyses}

In the first Emergence of the Unmarked (TETU) analysis proposed by McCarthy and Prince (1994a, 1995), it was shown that a markedness constraint $M$ which may be inactive in all other conditions in a language may surface in that language in an environment conditioned by the presence of a specific morpheme. This analysis was posited for reduplication phenomena showing sensitivity to markedness 
preferences. The ranking proposed by McCarthy and Prince for such phenomena was one in which the markedness constraint $\mathrm{M}$ is ranked lower thanthe faithfulness constraint IO-FAITH. The markedness requirement $\mathrm{M}$ emerges in the language because it outranks other faithfulness constraints on BaseReduplicant Identity. Consequently, reduplicants obey the markedness constraint but violate the constraint requiring faithfulness to the base (Alderete et al. 1999; McCarthy and Prince 1994a). The surfacing of [Back] harmony in Assamese also shows that emergent unmarkedness may sometimes be underscored by phonological processes. I have offered an account that relies on positional faithfulness alongwith featural licensing, so that the analysis captures the desired effect that some instances of root controlled [Back] harmony are the result of emergent markedness restrictions.

In current OT approaches, problems presented by derived environment processes have been analyzed by revising the basic architecture of Optimality Theory. Approaches like that of local conjunction and comparative markedness try to address the difficulties presented by a process which is sensitive to a phonological derivation or a morphological boundary. Comparative markedness refers to differences between old and new markedness. Markedness constraints can refer to 'old' violations (those already underlyingly present) vs. 'new' violations (those created by Gen). In local conjunction approaches (as per Lubowicz 2002, 2005), DEE are seen to be a result of the conjunction of faithfulness and markedness constraints. The critiques in Sections 4.4 and 4.5 discuss the challenges that would be presented by Assamese if these approaches were applied to the data.

\subsection{The unsuitability of a local conjunction solution to Assamese derived environment effects}

Local constraint conjunction was first proposed by Smolensky (1995) as a proposal about the internal structure of constraints. Some proponents of local conjunction (LC) (Itô and Mester 2003c; Kirchner 1996; Moreton and Smolensky 1995) advocate for the local conjunction of faithfulness constraints only. We can compare the derived environment effects presented in this paper with the derived environment processes presented in Kiparsky (1993), Lubowicz (2003), and elsewhere. To analyze the problem of derived environment blocking effects (DEE), Lubowicz conjoins two constraints in order to explain phonological processes that are blocked in derived domains. The Assamese problem, where there is a double violation of faithfulness constraints in order to satisfy an otherwise low-ranked markedness constraint, may look like a classic case which requires an LC solution, where IDENT[Low] and IDENT[Back] are violated to satisfy the harmony constraint. However, LC will not be able to capture the intricacies of the derived environment phenomena in Assamese. Local conjunction would give us right results only in those cases where violations of IDENT[Back] as well as IDENT[Low] occur in order to produce Back harmony in the two initial syllables. Consequently, if we try to offer a Lubowicz style conjoined constraint $*[+$ Back - High $] \&$ IDENT[Low $]^{17}$ » IDENT[Back] solution to the Assamese problems described here, we can account for exceptional cases of [Back] harmony where there is anIDENT[Back] violation.

(61) $*$ [+Back -High]\&IDENT[Low] can predict /elehuwa/

\begin{tabular}{|l||c|c|}
\hline /Elah-uwa/ & $*[+$ Back - High]\&IDENT[Low] & IDENT[Back] \\
\hline \hline a. elohuwa & $* !$ & \\
\hline b. ${ }^{\circ}$ elehuwa & & $*$ \\
\hline
\end{tabular}

The tableau above shows where LC can work in Assamese. But this approach severely fails when both $*$ [+Back-High] \&IDENT[Low] are violated by the attested output in (62b) below. The local conjunction of the two constraints predicts the wrong output*[miselija], i.e. the candidate which does not violate $*[+$ Back-High $]$.

(62) *[+Back-High]\&IDENT[Low] cannot account for /misolija/

\begin{tabular}{|c|c|c|}
\hline /misa-[1]-ija/ & $*[+$ Back-High]\&IDENT[Low] & IDENT[Back] \\
\hline a. :misolija & $* !$ & \\
\hline b. miselija & & $*$ \\
\hline
\end{tabular}

The selection of the unattested *[miselija] shows that the LC solution does not capture the essential fact in Assamese that [Back] harmony is triggered only by sequences of mid vowels. While IDENT[Low] is always violated by these exceptional patterns, *[+Back -High] is also violated if there

\footnotetext{
${ }^{17}$ Alternatively, the conjoined constraint could also be *[-Back][+Back] \&IDENT[Low].The conjoining of this sequential markedness constraint with the faithfuness constraint would not lead to any improvement in the results predicted by LC.
} 
are no preceding front mid vowels because IDENT[Low] violations do not necessarily lead to IDENT[Back] violations. The pattern we need to analyze here is such that unfaithfulness to [Back] specifications is required in the presence of mid vowels only, to the exclusion of all others, and only in the position where it is adjacent to the triggering vowel. The LC approach, if successful, would have predicted alternations which are not noticed in any language, such as alteration of [+Back] values of all vowels which are underlyingly [+Back] and [-High] if there is any change in the value of [Low]. In reality, the attested alternations in Assamese are not so effusive and random, and they follow a pattern which eludes the LC analysis.

\subsection{Comparative markedness analysis}

Comparative markedness argues for a model of grammar where underlying segments violate 'markedness old' whereas derived segments are violated by 'markedness new'. Markedness constraints can refer to 'old' violations, i.e. those already underlyingly present. The same markedness constraints can incur 'new' violations which are created by Gen. This approach will not provide us with a correct analysis of the facts in Assamese. In Assamese, derived /o/ is permitted in certain contexts and there is no absolute ban on the occurrence of /o/ derived from /a/. The derived environment effect appears only in the presence of a preceding / $/ \mathcal{E} /$. This result seems intractable with the present theoretical tools offered by comparative markedness.

(63) A possible comparative markedness analysis

\begin{tabular}{|l|c|c|c|}
\hline /elah-uwa/ & $*[\mathrm{o}]_{\text {New }}$ & IDENT[Back] & $*[\text { o }]_{\text {Old }}$ \\
\hline \hline a. elohuwa & $* !$ & & \\
\hline b. ${ }^{*}$ elehuwa & & $*$ & \\
\hline
\end{tabular}

Candidate (63a) above violates the new markedness constraint $*[0]_{\mathrm{New}}$ at the expense of retaining its [Back] values and therefore incurs a fatal violation. Candidate (63b) avoids new violations of *[o] and is therefore selected as the optimal candidate. The tableau above shows that by adopting old and new versions of *[o], one would be able to allow for the well-formedness of [elehuwa] 'lazy'. However, the success of this candidate in this tableau will be misleading as $*[0]_{\text {New }}$ makes the incorrect prediction that derived [o] does not surface in Assamese. Its failure is captured by the tableau below:

(64) The failure of comparative markedness analysis

\begin{tabular}{|c|c|c|c|}
\hline /misa-[1]-ija/ & $*[\mathrm{o}]_{\mathrm{New}}$ & IDENT[Back] & $*[\mathrm{o}]_{\text {old }}$ \\
\hline a. : misolija & $* !$ & & \\
\hline b. ${ }^{\prime \prime \prime m i s e l i j a ~}$ & & * & \\
\hline
\end{tabular}

Candidate (64a) above fatally violates the new markedness constraint $*[0]_{\text {New. }}$. Candidate (64b) avoids new violations of $*[\mathrm{o}]$ and is therefore erroneously selected as the optimal candidate. This shows that comparative markedness is not a viable option for analyzing the derived environment effect in Assamese.

\section{Conclusion}

The exceptionally triggered vowel alternations discussed in this paper can be characterized as morphologically induced harmony, which is obtained at the cost of flouting the highly ranked phonological constraint IDENT[Low] (which prevents any alteration of the low vowel /a/). In the first case, the suffixal morphemes /-ija/ and /-uwa/ trigger exceptional alteration of the otherwise opaque vowel /a/. The resultant raising of / $\mathrm{d} /$ to a $[+\mathrm{ATR}]$ vowel in this context violates the constraint IDENT[Low], which is otherwise highly ranked in the phonology of Assamese. Secondly, this leads to the emergence of [Back] harmony whenever there is a preceding front mid vowel. In the rest of the paper, I describe these morpho-phonological interactions and discuss several aspects of locality and emergent unmarkedness which have consequences for theories of exceptions and DEEs.

The derived environment data show a DEE effect which is masked in the regular phonology. It only emerges as a consequence of raising in exceptional vowel harmony. The data show that this effect, although appearing in a derived domain, is a reflex of the grammar at large and is actually an emergent unmarkedness pattern. The analysis proposed in this section is superior to other competing analyses 
because it can effectively contain long distance effects in exceptions and it also shows how such restraining of harmony in the local domain may facilitate the emergence of the unmarked segment [e] and result in the process of [Back] harmony in Assamese.

This work also addresses the typology of exceptions in vowel harmony and shows that locality constrains exceptional harmony processes. In a strain different from Finley (2010), I have argued that exceptional triggers and exceptional undergoers are the only exceptional types which need to establish a harmonic relation with an adjacent element. Other exceptional patterns like blocking do not need any additional convention of locality as they behave like regular phonological blocking, which is also locally bound. Thus, this paper shows that exceptional triggering is the only truly local phenomena specific to exceptional vowel harmony. In all other types of exceptionalities, the facts require only mechanisms which are observable in other vowel harmony phenomena. The only type of exception that a theory of exceptional vowel harmony has to constrain is the total absence of exceptionally transparent vowels. This may boil down to the fact that transparent vowels make way for the interaction of two non-adjacent units, i.e. the trigger and the target.

This article is a contribution to the understanding of harmony processes in general. Vowel harmony is normally iterative, but iterativity caused by feature spreading in vowel harmony is typically myopic (Wilson 2003, 2006). In a typical harmonic environment, when a feature spreads to a neighboring element it is only sensitive to whether the neighboring segment can undergo harmony; harmony is not dependent on any element beyond the immediate segment in a string. If harmony is not dependent on factors beyond string-adjacency, the operation is dependent on local factors, not global ones. This paper demonstrates how exceptional and emergent processes in an iterative harmony language show harmony patterns which are determined strictly by local factors. However, this operation has to be different from locality in iterative harmony where a lack of morphological indexation allows harmony to proceed iteratively. In the case of DEEs and exceptional harmony, a preconceived idea of locality in iterative harmony would give rise to an analysis with pathological harmony. Although exceptions and DEE are different as phonological processes, the interaction of the two phenomena with vowel harmony shows that both are local.

\section{Acknowledgments}

This paper owes much of its existence to various people who have helped me in understanding the problem at hand, and primary among them is Joe Pater. I express my sincere gratitude to three anonymous reviewers for offering concrete suggestions to improve the paper. The associate editor Junko Itô helped in numerous ways with extensive comments and suggestions. This paper would not have been publishable without their valuable input. Another version of this paper was presented at the VIIth Asian GLOW colloquium in Hyderabad and I am grateful to the audience, especially Paul Kiparsky, for comments. Earlier versions of this work have benefitted from the comments of Wim Zonneveld, Janet Grijzenhout, and Kie Zuraw. All remaining errors are mine.

\section{References}

Alderete, John.2001. Dominance effects as transderivational anti-faithfulness. Phonology 18: 201-253.

Anderson, Stephen R. 1980. Problems and perspectives in the description of vowel harmony.In Issues in vowel harmony, ed. Robert M. Vago, 1-48. Amsterdam: John Benjamins.

Anttila, Arto. 2002. Morphologically conditioned phonological alternations. Natural Language and Linguistic Theory 20(1):1-42.

Aoki, Haruo. 1966. Nez Perce vowel harmony and proto-Sahaptian vowels. Language42: 759-767.

Archangeli, Diana and Douglas Pulleyblank. 1989. Yoruba vowel harmony. Linguistic Inquiry20:173217.

Archangeli, Diana and Douglas Pulleyblank. 1993. Optimality, grounding theory, and rule parameters. Paper presented at The Rutgers optimality workshop, Rutgers University.October, 1993.

Archangeli, Diana and Douglas Pulleyblank. 1994. Grounded phonology. MIT Press: Cambridge.

Bakovic, Eric. 2000. Harmony, dominance and control. PhD dissertation, Rutgers University, New Brunswick.

Beckman, Jill.1998. Positional faithfulness.PhD dissertation, University of Massachusetts, AmherstRutgers Optimality Archive 1297. http://roa.rutgers.edu/.

Benua, Laura. 2000. Phonological relations between words. New York: Garland.

Butska, Luba. 1998. Faithfulness to [voice] in Ukrainian: An analysis of voicing alternations within Optimality Theory. InRuLing Papers 1: Working papers from Rutgers University, eds. R. Artstein and M. Holler, 59-73. New Brunswick: Rutgers University. 
Calabrese, Andrea. 1988. Towards a theory of phonological alphabets. PhD dissertation, MIT, Cambridge.

Cho, Mi-Hui. 1994. Vowel harmony in Korean: A grounded phonology approach. PhD dissertation, Indiana University, Bloomington.

Chomsky, Noam and Morris Halle. 1968. Sound pattern of English. New York: Harper and Row.

Crothers, John.1978. Typology and universals of vowel systems. In Universals of human language.Vol 2: Phonology, eds. Joseph Harold Greenberg, Charles Albert Ferguson, Edith Moravcsik,93-152. Stanford: Stanford University Press.

Dimmendaal, Gert. 1983. The Turkana language. Foris: Dordrecht.

Flack, Kathryn. 2007. Templatic morphology and indexed markedness constraints. Linguistic Inquiry 38(4): 749-758.

Finley, Sara.2010. Exceptions in vowel harmony are local. Lingua120: 1549-1566

Fukuzawa, Haruka.1999. Theoretical implications of OCP effects on features in optimality theory. $\mathrm{PhD}$ dissertation, University of Maryland, College Park.

Gelbart, Ben. 2005. The role of foreignness in phonology and speech perception. PhD dissertation, University of Massachusetts, Amherst.

Gouskova, Maria. 2007. The reduplicative template in Tonkawa. Phonology 24: 367-396.

Goswami, Golok Chandra. 1982. Structures of Assamese. Gauhati University: Department of Publication.

Hall, Beatrice L. and Hall, R.M.R. and Pam, Martin D. 1974. African vowel harmony systems from the vantage point of Kalenjin.Afrika und Ubersee 57:241-267.

Hall, Beatrice L. and R.M.R. Hall. 1980. Nez Perce vowel harmony: An Africanist explanation and some theoretical questions. In Issues in vowel harmony: The Proceedings of the CUNY linguistics conference on vowel harmony, ed. Robert M. Vago. Amsterdam: John Benjamins

Harris, James. W. 1983. Syllable structure and stress in Spanish: A nonlinear analysis. Cambridge, MA: MIT Press.

Harris, James. W. 1986a. Epenthesis processes in Spanish. In Studies in Romance languages, eds. Carol Neidle and Rafael A. Nunez-Cedeno, 107-22. Dordrecht: Foris.

Harris, James. W. 1986b. El modelo multidimensional de la fonologia y dialectologia Caribena.In Estudios sobre la fonologia del Espanol del Caribe, eds. Rafael A. Nunez-Cedeno, Iraset Paez Urdaneta and Jorge M. Guitart, 41-51. Caracas: La Casa de Bello.

Hansson, Gunnar. 2001. Theoretical and typological issues in consonant harmony. PhD dissertation, University of California, Berkeley.

Horwood, Graham. 1999. Anti-faithfulness and subtractive morphology. Rutgers Optimality Archive 901. http://roa.rutgers.edu/.

Inkelas, Sharon. 1998. The theoretical status of morphologically conditioned phonology: A case study from dominance. In Yearbook of morphology1997, eds. Geert Booij and Jaap van Marle, 121-155. Amsterdam: Springer.

Hem Chandra Barua. 1900/2007. Hemkosha- The Assamese-English dictionary. Gauhati: Hemkosh Prakashan.

Inkelas, Sharon and Cemil Orhan Orgun. 1995. Level ordering and economy in the lexical phonology of Turkish. Language 71:763-793.

Inkelas, Sharon and Cemil Orhan Orgun.1998. Level (non)ordering in recursive morphology: Evidence from Turkish. In Morphology and its relation to phonology and syntax, eds. Steven Lapointe, Diane Brentari, and Patrick Farrell, 360-392. Stanford: CSLI.

Inkelas, Sharon and Cheryl Zoll. 2005. Reduplication: Doubling in morphology. Cambridge: Cambridge University Press.

Inkelas, Sharon and Cheryl Zoll. 2003. Is grammar dependence real? Rutgers Optimality Archive 303. http://roa.rutgers.edu/.

Itô, Junko and Armin Mester. 1999. The Phonological lexicon. In Handbook of Japanese linguistics, ed. Natsuko Tsujimura, 62-100.Oxford: Blackwell.

Itô, Junko and Armin Mester. 2001. Covert generalizations in optimality theory: The role of stratal faithfulness constraints. Studies in Phonetics, Phonology, and Morphology 7.2: 273-299.

Kaun, Abigail. 1995. The typology of rounding harmony: An optimality theoretic approach. $\mathrm{PhD}$ dissertation, University of California,Los Angeles.

Kiparsky, Paul. 1973. Abstractness, opacity, and global rules. In Three dimensions of linguistic theory, ed. Osamu Fujimura, 57-86. Taikusha: Tokyo.

Kim, Jong-Kyoo. 2000. Quantity-sensitivity and feature-sensitivity of vowels: A constraint-based approach to Korean vowel phonology. PhD dissertation, Indiana University, Bloomington.

Kiparsky, Paul. 1981. Vowel harmony. Ms., Massachusetts Institute of Technology, Cambridge.

Kiparsky, Paul. 1982. Explanation in phonology. Dordrecht: Foris.

Kiparsky, Paul.1993. Blocking in non-derived environments. In Studies in lexical phonology, eds. Sharon Hargus and Ellen Kaisse,277-314.New York: Academic Press. 
Kirchner, Robert. 1996. Synchronic chain shifts in optimality theory. Linguistic Inquiry27: 341-350.

Krämer, Martin. 2001a. Yucatec Maya vowel alternations: Harmony as syntagmatic identity. Zeitschrift für Sprachwissenschaft 20: 175-217.

Krämer, Martin. 2003. Vowel harmony and correspondence theory. Berlin: Mouton de Gruyter.

Kraska-Szlenk, Iwona. 1997. Exceptions in phonological theory. Proceedings of the 16th international congress of linguists. Pergamon: Oxford

Lee, Duck-Young. 1998. Korean phonology. Munich: Lincom Europa.

Lombardi, Linda. 1994. Laryngeal features and laryngeal neutralization. New York: Garland.

Lombardi, Linda. 1995a. Laryngeal neutralization and syllable wellformedness.Natural Language and Linguistic Theory 13:39-74.

Lombardi, Linda. 1995b. Why place and voice are different: Constraint-specific alternations in optimality theory. Rutgers Optimality Archive 105. http://roa.rutgers.edu/.

Lombardi, Linda. 1996a. Positional faithfulness and voicing assimilation in optimality theory. Ms., University of Maryland, College Park.

Lubowicz, Anna. 2002. Derived environment effects in optimality theory. Lingua 112: 243-280.

Lubowicz, Anna. 2005. Locality of conjunction. In Proceedings of the west coast conference on formal linguistics 24, eds. John Alderete, Chung-hye Han, and Alexei Kochetov, 254-262. Cambridge, MA: Cascadilla Press.

Mahanta, Shakuntala. 2008. Locality and directionality in vowel harmony. Utrecht: LOT Dissertation Series 173.

McCarthy, John and Alan Prince. 1993. Generalized alignment. In Yearbook of morphology, eds. Geert Booij and Jaap van Marle, 79-153. Dordrecht: Kluwer.

McCarthy, John, and Alan Prince. 1993.The emergence of the unmarked. In Proceedings of the northeastlinguistic societymeeting 24, ed. Mercè Gonzàlez,333-379. Amherst: Graduate Linguistic Student Association.

McCarthy, John.2003a. Comparative markedness.Theoretical Linguistics 29:1-51.

McCarthy, John. 2003b. OT constraints are categorical. Phonology 20:75-138.

McCarthy, John. 2005. Taking a free ride in morphophonemic learning. Catalan Journal of Linguistics 4: $19-56$.

McCarthy, John and Matthew Wolf. 2005. Less than zero: Correspondence and the null output. Rutgers Optimality Archive 722. http://roa.rutgers.edu/.

Mohanan, Karuvannur P. 1986. The theory of lexical phonology. Dordrecht: Reidel.

Moreton, Elliott and Paul Smolensky.2002. Typological consequences of local constraint conjunction. In Proceedings of the west coast conference on formal linguistics 21, eds. Line Mikkelsen and Christopher Potts, 306-319. Cambridge, MA: Cascadilla Press.

Orgun, Cemil Orhan. 1996. Sign-based morphology and phonology: With special attention to optimality theory. PhD dissertation, University of California, Berkeley.

Orgun, Cemil Orhan. 1998. Cyclic and noncyclic effects in a declarative grammar. In Yearbook of morphology1997, eds. Geert Booij and Jaap van Marle, 179-218. Amsterdam: Springer.

Orgun, Cemil Orhan. 1999. Sign-based morphology: A declarative theory of phonology-morphology interleaving. In The derivational residue in phonological optimality theory, eds. Ben Hermans and Marc van Oostendorp, 247-267. Amsterdam: John Benjamins.

Orgun, Cemil Orhan and Sharon Inkelas. 2002. Reconsidering bracket erasure. In Yearbook of morphology2001, eds. Geert Booij and Jaap van Marle, 115-146. Amsterdam: Springer.

Mitsuhiko Ota. 2004. The learnability of the stratified phonological lexicon. Journal of Japanese Linguistics 20: 19-40.

Pater, Joe. 2000. Nonuniformity in English stress: The role of ranked and lexically specific constraints. Phonology 17:237-274.

Pater, Joe. 2006. The locus of exceptionality: Morpheme-specific phonology as constraint indexation. In University of Massachusetts occasional papers in linguistics 32: Papers in optimality theory III, eds. Leah Bateman, Michael O'Keefe, Ehren Reilly, and Adam Werle, 1-36. Amherst: Graduate Linguistic Student Association.

Pater, Joe. 2009. Morpheme-specific phonology: Constraint indexation and inconsistency resolution. In Phonological argumentation: Essays on evidence and motivation. ed. Steve Parker, 123-154. London: Equinox.

Postal, Paul M. 1968.Mohawk vowel doubling.International Journal of American Linguistics 35: 291298.

Prince, Alan and Paul Smolensky. 1993/2004. Optimality Theory: Constraint interaction in generative grammar. RuCCS Technical Report \#1, Rutgers center for cognitive science, Rutgers University, Piscataway, NJ, 1993. Revised version published 2004. Optimality Theory: Constraint interaction in generative grammar. Malden: Blackwell.

Riggle, Jason and Colin Wilson. 2004. Local optionality. Poster presented at The north east linguistic society meeting 35.October, 2004. 
Shademan, Shabnam. 2003. Epenthetic vowel harmony in Farsi. Paper presented at The twentysecond west coast conference on formal linguistics, University of California, San Diego.March, 2003.

Smolensky, Paul. 1995. On the structure of the constraint component Con of UG. Paper presented at University of California, Los Angeles. April, 1995.

Stewart, John M. 1967.A theory of the origin of Akan vowel harmony.In Proceedings of the sixth internationalcongress of phonetic sciences 1967, eds. Bohuslav Hala, Milan Romportl and Premysl Janot, 863-64. Prague: Academic publishing house of the Czechacademy of sciences.

Steriade, Donca. 1987. Locality conditions and feature geometry. Proceedings of the northeast linguistic society 17,eds. Joyce McDonough and Bernadette Plunkett, 595-617. Amherst: GSLA..

Stewart, John. 1971. Niger-Congo, Kwa. In Current trends in linguistics 7: Linguistics in sub-Saharan Africa,ed. Thomas A. Sebeok,179-212.The Hague: Mouton.

Tunga, Sudhanshu. 1995. Bengaliand other related dialects of South Assam. New Delhi: Mittal.

Woock, Edith B. and Michael Noonan. 1979. Vowel harmony in Lango.Proceedings of the Regional Meeting of the Chicago Linguistics Society 15:20-29.

Wilson, Colin. 2003. Analyzing unbounded spreading with constraints: Marks, targets and derivations. Ms.,University of California, Los Angeles.

Wilson, Colin. 2006. Unbounded spreading is myopic. Paper presented at Theworkshop on current perspectives on phonology, Indiana University, Bloomington.June, 2006.

Zonneveld, Wim. 1978. A formal theory of exceptions in generative phonology. Lisse: Peter de Ridder Press. 